Check for updates

Cite this: RSC Adv., 2018, 8, 29400

\title{
Recent development of boronic acid-based fluorescent sensors
}

\author{
Guiqian Fang, ${ }^{\text {abcd }}$ Hao Wang, ${ }^{\text {abcd }}$ Zhancun Bian, ${ }^{\text {abcd }}$ Jie Sun, (D) abcd Aiqin Liu, ${ }^{\text {abcd }}$ \\ Hao Fang, ${ }^{e}$ Bo Liu, ${ }^{\text {abcd }}$ Qingqiang Yao ${ }^{\text {abcd }}$ and Zhongyu Wu (D) *abcd
}

As Lewis acids, boronic acids can bind with 1,2- or 1,3-diols in aqueous solution reversibly and covalently to form five or six cyclic esters, thus resulting in significant fluorescence changes. Based on this phenomenon, boronic acid compounds have been well developed as sensors to recognize carbohydrates or other substances. Several reviews in this area have been reported before, however, novel boronic acid-based fluorescent sensors have emerged in large numbers in recent years. This paper reviews new boronbased sensors from the last five years that can detect carbohydrates such as glucose, ribose and sialyl Lewis $A / X$, and other substances including catecholamines, reactive oxygen species, and ionic compounds. And emerging electrochemically related fluorescent sensors and functionalized boronic acid as new materials including nanoparticles, smart polymer gels, and quantum dots were also involved. By summarizing and discussing these newly developed sensors, we expect new inspiration in the design of boronic acid-based fluorescent sensors.

rsc.li/rsc-advances

\section{Introduction}

Different elements form a rich and colorful world dynamically, and they are in diverse forms of existence through a series of physical effects and biochemical reactions. To accurately understand these processes, we need to give consideration to their existence at the molecular level. The objects of scientists' research vary from single ions to complex and changeable proteins. In order to deeply understand them, scientists have devoted much time to developing effective recognizing tools, and molecular recognition sensors are utilized extensively. Normally, two conditions should be taken into consideration while fabricating an ideal sensor. First, it is necessary to have a specific recognition site that combines with objects such as the human microenvironment of ions, carbohydrates, peptides, etc. Second, the dynamic changes made by these combinations can be detected by monitoring environment, and some of the extensively used reporters are optical and electrical. ${ }^{1}$ The interactions of recognition originate from noncovalent bonding, such as hydrogen bonds, van der Waal's forces, $\pi-\pi$ interactions, electromagnetic effects and so on, extending to

${ }^{a}$ School of Medicine and Life Sciences, University of Jinan-Shandong Academy of Medical Sciences, Jinan 250200, Shandong, China. E-mail: wu_med@foxmail.com

${ }^{b}$ Institute of Materia Medica, Shandong Academy of Medical Sciences, Jinan 250062, Shandong, China

'Key Laboratory for Biotech-Drugs Ministry of Health, Jinan 250062, Shandong, China ${ }^{d}$ Key Laboratory for Rare \& Uncommon Diseases of Shandong Province, Jinan 250062, Shandong, China

${ }^{e}$ Department of Medicinal Chemistry, School of Pharmaceutical Sciences, Shandong University, Jinan, Shandong 250012, China covalent bonds and other sensory systems. ${ }^{2,3}$ In recent years, using boronic acid groups to fabricate a variety of fluorescent sensors have attracted great interest among scientists. Based on the principle that boronic acid forms a reversible five- or sixmembered cyclic boronic esters with cis-1,2- or 1,3 -diols, ${ }^{4}$ the fabrication of boronic acid fluorescent sensor extends from boronic acid-appended molecular sensors to apply unconventional smart new materials, including boronic acidfunctionalized polymers, boronic acid-modified nanoparticles, and boronic acid-based electrochemical sensors. ${ }^{4,5}$ For instance, boronic acid-functionalized hydrogels are important smart materials that can be used to fabricate the self-controlled insulin releasing device in the biomedical field. ${ }^{6}$ Hydrogels endows special properties to boronic acid sensors due to their compatibility with organisms to a certain degree. ${ }^{7,8}$ Recently, numerous new types of boronic acid sensors have been fabricated to detect blood glucose concentrations, ${ }^{9-13}$ ionic compounds, ${ }^{14-17}$ traces of water in solvents, ${ }^{18,19}$ hydrogen peroxide $\left(\mathrm{H}_{2} \mathrm{O}_{2}\right),{ }^{20-22}$ catecholamines, ${ }^{23}$ as well as using boronic acids as biochemical tools for various applications, including tumor cell imaging, ${ }^{24,25}$ enzyme inhibitors ${ }^{26}$ and cell delivery systems. ${ }^{27}$ Therefore, the boron-based fluorescent sensor is still hot in today's research. This review summarized the recent development of boronic acid-based fluorescent sensors for carbohydrates, catecholamines, reactive oxygen species (ROS), ionic compounds and new materials. Although numerous remarkable achievements have been mentioned in previous reviews ${ }^{28}$ some areas of research have faded and many new and exciting areas have developed. In order to update knowledge of this rapidly developing field, it is worth highlighting their 
merits and discussing the remaining shortcomings, as well as the development perspective of fabricating boronic acid sensors. It is also hoped that inspires others to exploit novel sensing strategies.

\section{Carbohydrates boronic acid sensors}

As the important material basis, carbohydrates widely distribute in the body and maintain the normal operation of life. They are usually divided into mono-, di-, and polysaccharides, which play numerous roles in nature. For example, glucose serves as the primary form of energy for basic life processes such as nervous system regulation, cell proliferation, etc. Cellulose endows nature with structural rigidity. Starch and glycogen can serve as energy reserves to sustain life. In addition, they can combine with other molecules to form glycoproteins, glycolipids and so on, ${ }^{29}$ which play key roles in many biological basic activities such as cancer migration, ${ }^{30}$ cell fusion, ${ }^{31}$ protein function regulation ${ }^{32}$ and embryo development. ${ }^{33}$ Consequently, the recognition of carbohydrates in the medical, cell biology and other life sciences is of great significance. ${ }^{34}$

\subsection{Chemical basis for the combination of boronic acid and carbohydrates}

The initial study of forming reversible covalent bonds between boronic acids and 1,2- or 1,3-diols can be traced back to 1959 . Lorand and Edwards compared different covalent bond constants between the phenylboronic acids (PBA) and diols compounds involving saccharides via the observation of a $\mathrm{pH}$ drop. ${ }^{35}$ As depicted in Fig. 1, boronic acid interacts with water, resulting in a rapid transformation of the boron atoms from the trivalent plane $\mathrm{sp}^{2}$ (neutral) form 1 to the tetravalent tetrahedral $\mathrm{sp}^{3}$ (anion) form 2, and then releasing the proton. Due to the unique electron configuration of the elemental boron element 5 , the electron configuration $1 \mathrm{~s}^{2} 2 \mathrm{~s}^{2} 2 \mathrm{p}^{1}$ allows the form of three covalent bonds in the $\mathrm{sp}^{2}$ geometry. In the $\mathrm{sp}^{2}$ hybrid conformation, boron has only 6 valence electrons and can accept an electron pair, thus it is Lewis acid. Namely, boron has an

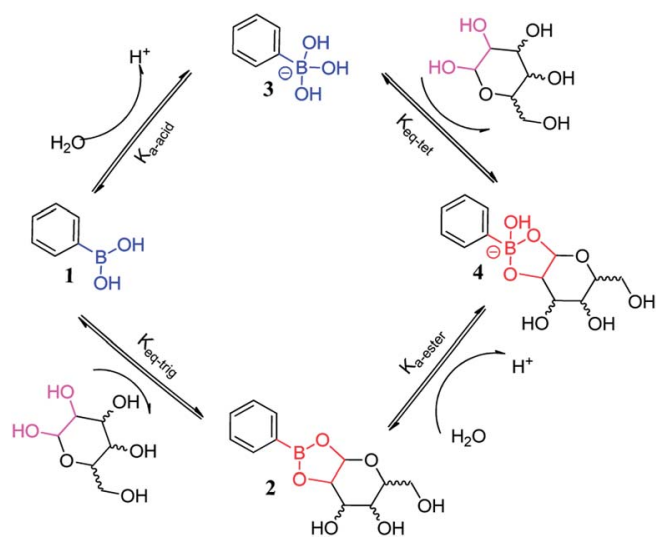

Fig. 1 Transformation of boronic acid to boronic ester. ${ }^{37}$ "electron hole" that interacts with the Lewis base, thereby forming a covalent bond with the tetrahedral $\mathrm{sp}^{3}$ geometry. It is an acid-base reaction that applies to the formation of borate ester. Davis et al. reported the relative rates of cyclic boronic esters, manifesting that the six-membered rings are thermodynamically more stable than the five-membered rings. ${ }^{5}$ Due to boronic acid and borate are likely to exist in two different hybrid forms of $\mathrm{sp}^{2}$ or $\mathrm{sp}^{3}$, there are three processes in the boratesugar interaction process, and the equilibrium constant is expressed by $K_{\text {trig. }}$. The second equilibrium is the process of $\mathrm{sp}^{3}$ hybridized borate anions 3 to borate ester anions 4 whose equilibrium constant is called $K_{\text {tet }}$. These two equilibrium constants alone can't really reflect the true situation of boronic acid combined with carbohydrates. Thus the third general combination constant $K_{\text {eq }}$ is often used, regardless of the specific hybrid state of boron. Later, Wang et al. found that $K_{\text {tet }}$ was actually measured by the $\mathrm{pH}$ drop method, and $K_{\text {eq }}$ was measured by spectroscopy. ${ }^{36,37}$ Therefore, when comparing the literature value, we need to pay special attention to the specific method of determining the binding constant.

\subsection{D-Glucose boronic acid sensors}

As a basic necessity of organisms, D-glucose plays an important role in biological processes. Humoral abnormal glucose level is a warning signal for medical conditions, and the development of selective glucose sensors for clinical and biomedical applications has become a crucial goal in the field of boronic acidbased chemical sensing. The selectivity of boronic acid for fructose has a higher abundance than glucose, thus reversing the intrinsic binding property has been the focus of early studies. ${ }^{4}$ The selectivity of glucose can be achieved via molecular design, ${ }^{38}$ and this technology is maturing, ${ }^{13}$ and recent developments tend to produce glucose optical responses by inducing nanoscale self-assembly of boronic acid-containing amphiphiles or other materials. ${ }^{39}$ This section will briefly introduce fluorescent sensors that were fabricated with anthracene, pyrene, heterocyclic ring as fluorescent units, and then the analysis of ribose, ${ }^{40}$ sialic acids, ${ }^{25,41}$ glucosamine, ${ }^{42} \alpha$ hydroxy carboxylate, ${ }^{43}$ ATP, ${ }^{44,45}$ amyloid- $\beta$ plaques ${ }^{46}$ fluorescent sensors are followed. This paper summarized the unique design ideas of these fluorescent sensors, the luminescence response mechanisms and the development perspective in the future.

2.2.1. Anthracene boronic acid sensors for D-glucose (Table 1). The first application of boronic acid compounds as fluorescent sensors dates back to 1992. Czarnik et al. reported the first anthracene boronic acid sensor $5 .^{47}$ This work has a great significance in the development of boronic acid sensors. Schwarz et al. reported that anthracene has higher fluorescence quantum yields compared to benzene and naphthalene. ${ }^{48}$ It is probably ascribed to the influence of the longer conjugated rigid planar structure. Anthracene has a stronger UV absorption (K band) in $\pi \rightarrow \pi^{*}$ transition. Therefore, Czarnik devised boronic acid sensor 5 using anthracene as a fluorescent unit, which recognizes D-fructose selectively in aqueous solution at $\mathrm{pH}$ 7.4. The sensor 5 belongs to excited state internal charge transfer (ICT), composed of anthracene unit and the boronic 
Table 1 Key information of anthracene boronic acid sensors D-glucose

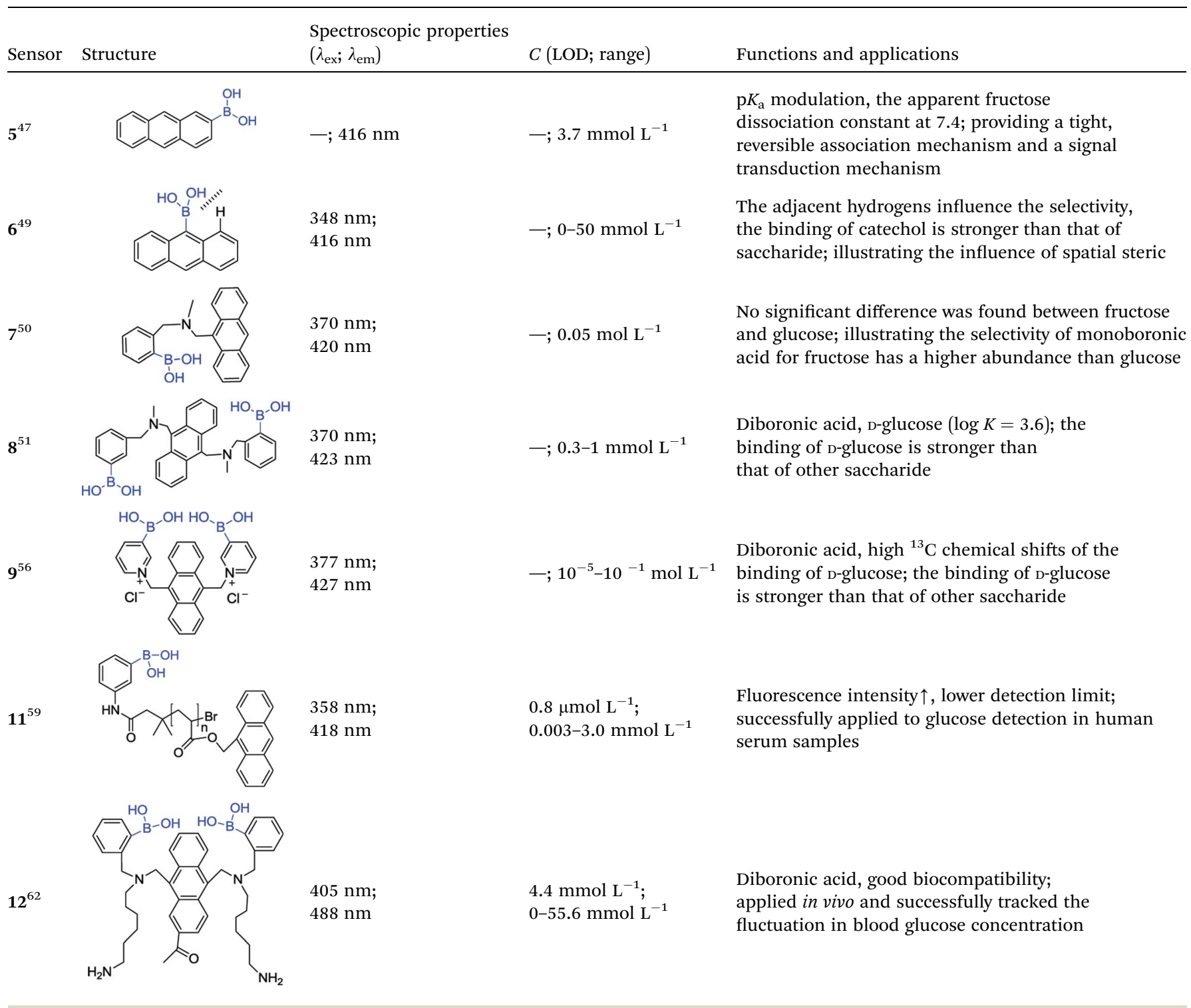

acid unit. In ICT systems, heteroatoms or strong-inducing functional groups can lead to an imbalanced electron density in the excited state of the molecule, thereby the favorable dipole-dipole interaction is increasing between the fluorophore and the surrounding solvent shell. ${ }^{1}$ Interestingly, they found that sensor 6 has a smaller fluorescence change, ascribed to the influence of the adjacent hydrogens. ${ }^{49}$ Those studies showed that $\mathrm{p} K_{\mathrm{a}}$ is a viable mechanism for signal transduction of carbohydrates bindings, providing some experiences for the future design of this type sensor. First, a tight, reversible association mechanism is needed. Second, the fluorescence assay required a signal transduction mechanism.

Subsequently, Shinkai et al. reported the anthracene monoboronic acid sensor 7 selectively recognizing $D$-fructose and the anthracene diboronic acid sensor 8 which selectively recognizes D-glucose. ${ }^{50,51}$ The sensor 7 was combined with carbohydrates to form $7 \mathbf{a}$, and its $\mathrm{N}-\mathrm{B}$ bond interaction of $7 \mathbf{a}$ was enhanced, which hindered the photoinduced electron transfer (PET) process from the tertiary amino group to the anthracene fluorophore. PET mechanism is generally believed that the aromatic ring electrons can be excited to the vibrational energy level of the first electron excited state or higher excited state after the aroma system is excited by the excitation light, and then it reaches the lowest vibrational energy level of the first excited singlet state after the internal energy conversion or vibration relaxation process. Finally, it returns to the ground state in the form of radiation to produce fluorescence. ${ }^{52}$ If there are nitrogen atoms and other atoms in the molecule, due to the energy of the lone pair electrons is between the ground state and the singlet state, the solitary electrons can transfer to the aromatic ring of the electron deficient and occupy its orbit, resulting that the original excitation of the electrons can't return to ground state, and can't produce fluorescence. Thus this combination brings great changes in the fluorescence 
properties that can be applied to detect specific carbohydrates. ${ }^{53,54}$ The discovery of PET mechanism will contribute in the future study of fluorescent sensors. However, the PET mechanism is not consistent with all data based on boronic acid sensors. Recently, Sun et al. proposed internal conversion mechanisms supported by three aspects. First, the receptors and its complexes with fructose are solvent-inserted without B-N interaction. Second, these sensors were also verified to not be aggregated. Third, there was no fluorescence response upon binding fructose while the $-\mathrm{B}(\mathrm{OH})_{2}$ was converted to the $-\mathrm{B}(\mathrm{OMe})_{2}$ groups in pure methanol. ${ }^{55}$
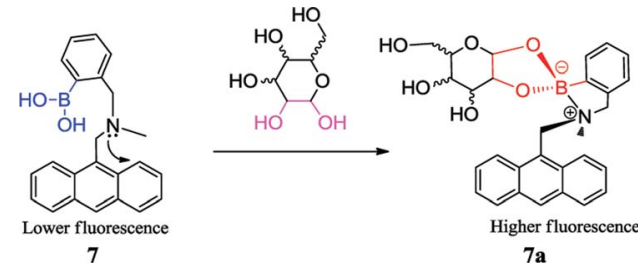

Similarly, anthracene was used as the fluorescent unit of sensor 8, but its selectivity was reversed because of bearing multiple boronic acid groups. Based on the above studies, Eggert et al. fabricated the sensor 9 that has a better selectivity for D-glucose, compared to fructose and mannose, and its stable complex structure was confirmed by ${ }^{1} \mathrm{H}$ and ${ }^{13} \mathrm{C}$ NMR data. ${ }^{56}$ However, this was a part of the story. Diboronic acid sensors research was expanded by other groups. ${ }^{57}$ Those studies give us a new insight: the inherent selectivity of boronic acid sensors to specific carbohydrates can be controlled by molecular design to form diboronic acid, which has better fluorescence selectivity through comfortable spatial position between the two boronic acids. Later, Mulla et al. took advantage of this feature and fabricated the sensor $\mathbf{1 0}$ containing a redox-active tetrathiafulvalene (TTF) unit and two boronic acid groups to selectively recognize carbohydrates. ${ }^{58}$

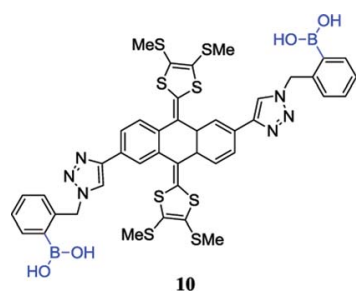

Recently, Wang et al. reported a sandwich boronate affinity sorbent assay (SBASA) for glucose detection. Sensor 11 was synthesized with anthracene group as a fluorescent monomer. ${ }^{\mathbf{9}}$ This method has a higher selectivity, a wider linear range $(0.003$ to $\left.3.0 \mathrm{mmol} \mathrm{L}^{-1}\right)$ and a lower detection limit $\left(0.8 \mu \mathrm{mol} \mathrm{L}{ }^{-1}\right)$. Moreover, it was successfully applied to glucose detection in human serum samples.

With the further improvement of technology, the selectivity of diboronic acid to glucose has been applied to the study of living animals. Takeuchi et al. utilized the anthracene boronic acid sensor 12 reported by Shinkai et al. ${ }^{60}$ to fabricate injectablesized fluorescent beads with uniformity and high throughput via polymerization. Those fluorescent beads were applied in vivo successfully by implanting fluorescent beads into the ear skin of mice for continuous glucose monitoring. As a result, it was found that the fluorescence intensity successfully tracked the fluctuation in blood glucose concentration from $0 \mathrm{mg} \mathrm{dL} \mathrm{d}^{-1}$ to $1000 \mathrm{mg} \mathrm{dL}{ }^{-1} \cdot{ }^{61}$ Subsequently, Takeuchi et al. went on further investigation by improving the polymerization technique. ${ }^{62}$ Hydrogel fibers were fabricated, which could stay in mice for up to 140 days. When implanted, they can control and quantify the amount of fluorescence. Moreover, they are easily removed from the body and have better applicability.
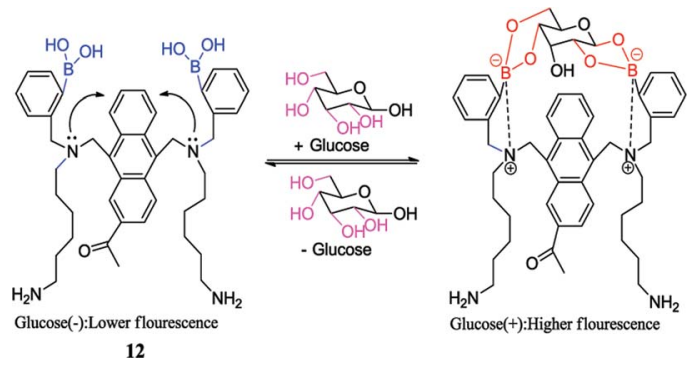

2.2.2. Pyrene boronic acid sensors for D-glucose (Table 2). Pyrene belongs to the fused aromatic ring compounds, having highest fluorescence quantum yields among benzene, naphthalene and anthracene. ${ }^{48}$ And it is often used in the basic theory study in the field of fluorescent sensors. A basic sensor should have three essential components: acceptor units, linker units and fluorophore units. ${ }^{63}$ Based on this principle and the fluorescence resonance energy transfer (FRET) mechanism, James et al. fabricated a new boronic acid sensor 13. FRET is a nonradiative energy transition phenomenon. When the fluorescent substance is excited, if the energy difference between the ground state of the donor and the vibration energy of the first excited state is equivalent to that of the acceptor or the emission spectrum of the donor is effectively overlapped with the excitation spectrum of the acceptor, the donor will effectively generate the oscillating dipole, resonate with the dipole of the proximal acceptor and transfer the energy of the donor fluorophore to the acceptor fluorophore, resulting in a change in the fluorescence intensity of the system. ${ }^{64}$

As mentioned in the previous part, glucose selectivity can be achieved via exquisitely fabricating receptors with multiple boronic acid groups. Such a modular approach to saccharide recognition has been pioneered by James, ${ }^{65}$ Wang, ${ }^{66}$ Singaram, ${ }^{67}$ to name but just a few. The boronic acid sensor 13 contains two PBA groups for selectivity, two different fluorophores units and a hexamethylene unit as a linker. ${ }^{63}$ They found that hexamethylene was the best linker to obtain D-glucose selectivity. The emission wavelength of phenanthrene 15 (donor) was $369 \mathrm{~nm}$ and the excitation wavelength of pyrene 14 (acceptor) was $342 \mathrm{~nm}$. They were overlapped. The conjugate of sensor 13 and the D-glucose was irradiated with the excitation wavelength of phenanthrene (299 nm), and its emission wavelength was further as the excitation wavelength of pyrene. Finally, the fluorescence intensity increased 3.9 times at $397 \mathrm{~nm}$. At $299 \mathrm{~nm}$ and $342 \mathrm{~nm}$, the fluorescence enhancement of D-fructose was 1.9 fold and 3.2 fold, respectively. $\mathrm{D}$-glucose complex was a rigid 
Table 2 Key information of a pyrene boronic acid sensors for D-glucose

Fectroscopic properties
$\left(\lambda_{\text {ex }} \lambda_{\text {em }}\right)$$\quad \begin{aligned} & C \text { (LOD; range) } \\ & \text { Functions and applications }\end{aligned}$

$1: 1$ cyclic, while the $\mathrm{D}$-fructose complex was a flexible $2: 1$ acyclic. As shown in the results, the energy transfer from phenanthrene to pyrene in D-glucose complex is more effective than D-fructose complex. Thus D-glucose is responded by sensor 13. This study showed that two points should be taken into account while fabricating fluorescent sensors employing FRET mechanism as a method to enhance sensitivity and selectivity. First, energy transfer in donors and acceptors should have corresponding fluorescence relationships. Second, it is critical in this sensor that the two boronic acids groups have a comfortable spatial position. As such, there are some strict requirements in the use of the FRET mechanism, but it does offer another novel method to fabricate fluorescent sensors. Subsequently, FRET mechanism is widely used in boronic acidbased sensor development. ${ }^{23}$

Due to the complex process of improving glucose selectivity by synthesizing diboronic acid groups or multiple boronic acid groups, Huang et al. had been exploring novel sensing regimes to improve the inherent selectivity of simpler monoboronic acid sensor 16, as depicted in Fig. $2 .{ }^{12}$ It is generally accepted that binding affinity of the boronic acid with fructose is higher than that with glucose. The specific recognition of glucose can be explained by the stoichiometric point of glucose and fructose binding to boronic acid. In the presence of D-fructose, a boronic acid derivative was produced to form an amorphous $1: 1$ conjugates. Highly ordered $2: 1$ fluorescent conjugates were obtained in the presence of D-glucose. This sensor system utilized the selective sensing mechanism both of the interaction of boronic acid with diols and aggregation induced by pyridinium cation- $\pi$ interactions. The binding constants of PBA with D-fructose and D-glucose were 4365 and 110, respectively, while the binding constant of the sensor 16 with fructose and Dglucose were 353 and 1378, respectively. Huang et al. used this kind of property and knocked out the interference of D-fructose by PBA strongly selective binding to $\mathrm{D}$-fructose in the case of $\mathrm{D}$ glucose and D-fructose mixed solution. Under this treatment, the sensor 16 can more clearly recognize D-glucose.

2.2.3. Heterocyclic boronic acid sensors for D-glucose (Table 3). Due to a traumatic operation of the blood will make some patients have tensional and promote blood glucose, the test results can't correctly reflect the patients' true blood glucose levels. If chemosensors can be used for continuous, noninvasive study of changes in blood glucose levels, it will greatly facilitate the clinical treatment of diabetes and related scientific research. Badugu et al. fabricated a water-soluble sensors $\mathbf{1 7}$ for non-invasive and continuous glucose detection based on the interaction between the quaternary nitrogen of the 6-methoxyquinolinium nucleus and the boronic acid group. When they are fixed on contact lenses, it is possible to use for the detection of glucose concentration in intraocular liquids. ${ }^{68}$ Due to changes in the process of ICT, these sensors have good fluorescence intensity and suitable spectral properties, which can be excited by inexpensive lasers. In the PET mechanism, the fluorophore and the acceptor are generally joined together by

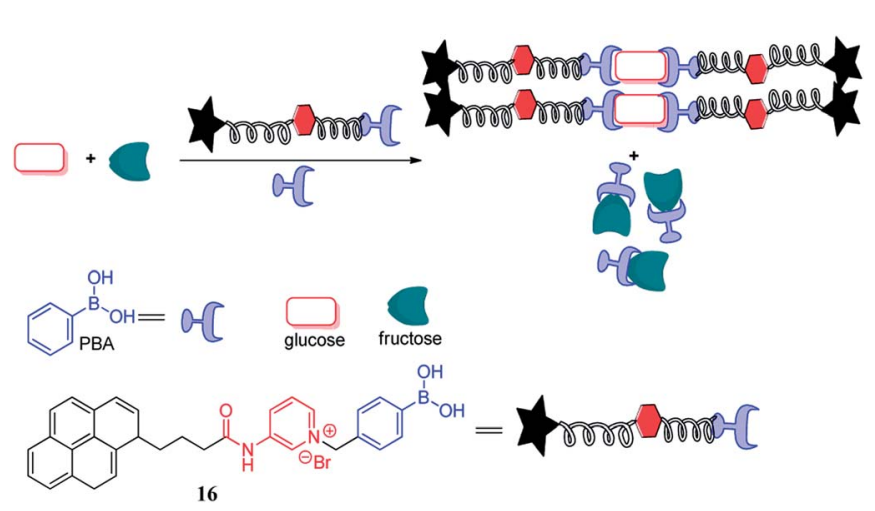

Fig. 2 Cartoon illustrating the knock-out effect of an excess of PBA. ${ }^{12}$ 
Table 3 Key information of heterocyclic boronic acid sensors for D-glucose

\begin{tabular}{llll}
\hline Sensor $\quad$ Structure & $\begin{array}{l}\text { Spectroscopic properties } \\
\left(\lambda_{\mathrm{ex}} ; \lambda_{\mathrm{em}}\right)\end{array}$ & $C$ (LOD; range) & Functions and applications \\
\hline
\end{tabular}

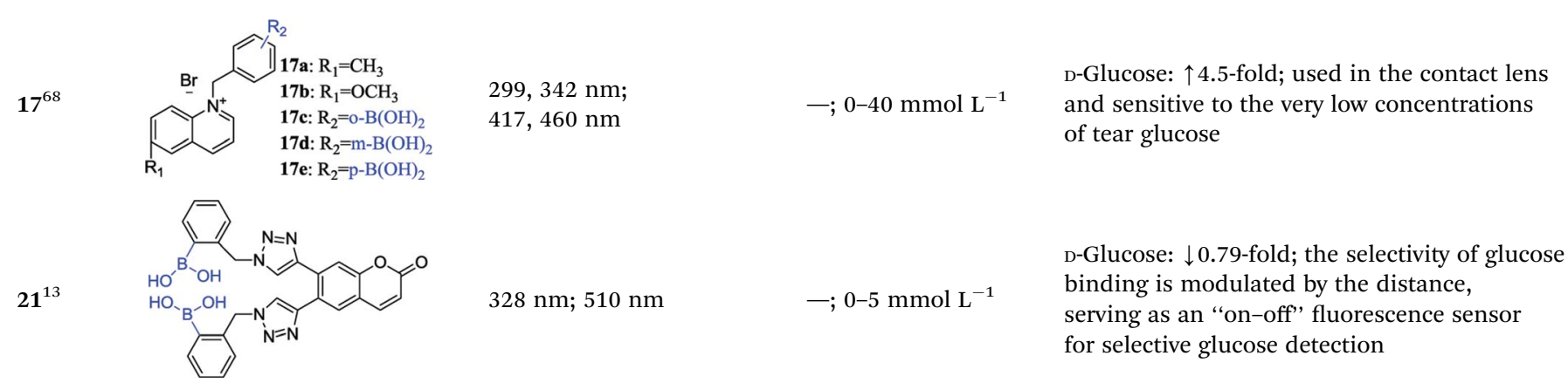

a linker, as the majority of the anthracene boronic acid sensors mentioned above. But an important feature of ICT mechanism is that the fluorophore is directly linked to the acceptor without the part of the linker. Push electrons (electron donors) and electron withdrawing groups (electron acceptors) are connected by the fluorophores of ICT fluorescent sensor to form a strong push-pull electron system, and the push electrons or electron withdrawing groups themselves act as recognition groups or a part of recognition groups. Normally, there is a certain conjugation between the acceptor and the fluorophore, and the whole molecule is a large $\pi$ system, and electronic groups or electron withdrawing groups can be used for acceptors.

Based on the encouraging research results of Badugu and coworkers, Bruen et al. conducted an in-depth study of the affordable, continuous and minimally invasive glucose monitoring system. ${ }^{69}$ The negatively-charged BA groups are capable of interacting with the positively-charged $\mathrm{N}$ present in the structure, resulting in fluorescence quenching. In contrast, indirect sensing using BA species has also been explored, such as the selection of fluorescein as fluorophore for pairing with BA species. Due to the electrostatic interaction of fluorescein and $\mathbf{1 7 c}$, the fluorescence of the fluorescein is quenched. However, with the addition of glucose, the $17 \mathrm{c}$ preferentially binds to the glucose, and the fluorescence intensity is restored by releasing the fluorescein.

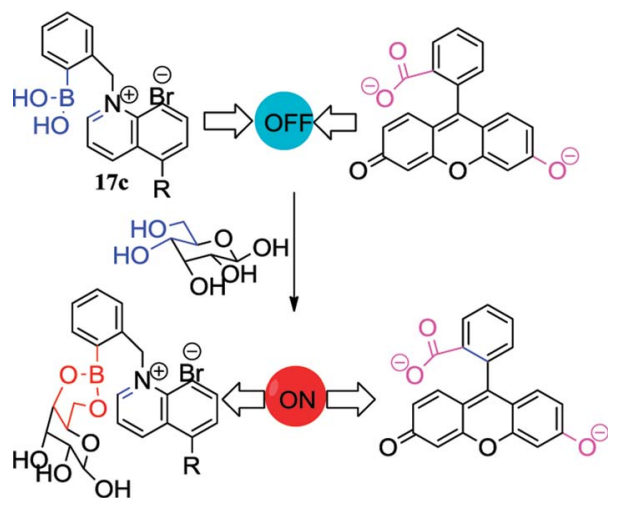

Brothers et al. reported the first O-BODIPY-glucose conjugate, which connected glucose directly to the dipyrrometheneboron difluoride (BODIPY) dye core by forming two $\mathrm{B}-\mathrm{O}-\mathrm{C}$ bonds, and the boronic acid recognition function and the fluorescence properties of BODIPY were combined into an entity. ${ }^{70}$ The reaction of Cl-BODIPY with glucose in acetonitrile formed a 1:1 $\alpha$-glucofuranose BODIPY complex 18, a 1:2 $\alpha$ glucofuranose BODIPY complex 19 and 1:2 $\alpha$-glucoseptanose BODIPY complex 20. To our knowledge, compound 20 is a novel example of unnatural septanose form of glucose. These fluorescent and hydrolytically stable conjugates open a new paradigm for carbohydrates labeling, sensing, and visualization by connecting strong fluorophores directly to carbohydrates rather than by long-range binding.

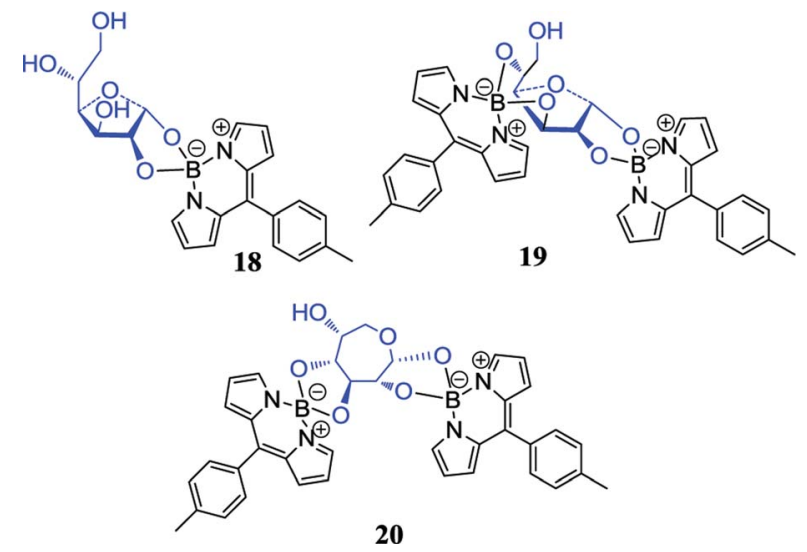

Recently, Zhai et al. reported the synthesis of a new bisboronic acid sensor using copper catalysed azide-alkyne cycloaddition (CuAAC) reactions and fabricated a new glucoseselective fluorescent sensor $\mathbf{2 1 .}^{\mathbf{1 3}}$ Interestingly, isothermal titration calorimetry (ITC) experiments showed that sensor has higher binding affinity toward glucose than fructose when two linkers with BPA were in the ortho-position. It manifested that the selectivity of glucose binding is modulated by the distance between the two boronic acid groups. Based on this principle, they fabricated sensor 21 subsequently. Excitingly, its fluorescent intensity shows compliance with ITC experimental prediction. 
In general, diol sensors are identified based on fluorophoreappended boronic acids, and their applications are often limited due to the lack of discrimination and one-dimensional response. However, Axthelm et al. designed a strategy that could compensate for this defect. ${ }^{71}$ The combination of fluorinated boronic acid-appended pyridinium salts 22 with ${ }^{19} \mathrm{~F}$ NMR spectroscopy enables the screening of a library of 59 biological analytes including monosaccharides. It is worth noting that these receptors are highly sensitive, selective and water-soluble. In addition, their ${ }^{19} \mathrm{~F}-\mathrm{NMR}$ analyte fingerprint is pH-robust making them particularly suitable for medical applications. For example, in a $188 \mathrm{MHz}$ NMR spectrometer, the concentration of glucose detected in synthetic urine samples was down to $1 \mathrm{mmol} \mathrm{L}^{-1}$.

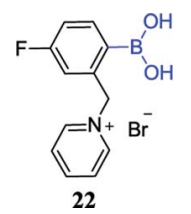

2.2.4. Other types of boronic acid sensors for D-glucose. Liu et al. fabricated a novel diboronic acid fluorescent sensor 23 based on tetraphenylethene (TPE), which limits the intramolecular rotation of the TPE aryl rotor by forming oligomers to respond toward glucose. ${ }^{57}$ Interestingly, the sensor 23 was mixed with D-fructose, D-galactose or D-mannose, but the light emission hardly changed. When the glucose concentration reached to $0.2 \mathrm{mmol} \mathrm{L}^{-1}$, two glucose units bound to the TPE, resulting in a decrease in the activity of the adduct formation, thereby releasing the fluorescence. When the concentration of glucose increased to $5 \mathrm{mmol} \mathrm{L}^{-1}$, the adduct further aggregated and the fluorescence intensity reached the maximum. Due to the oligomerization was a reversible equilibrium process, the adduct began to dissolve and the fluorescence intensity began to decrease when the concentration was further increased.

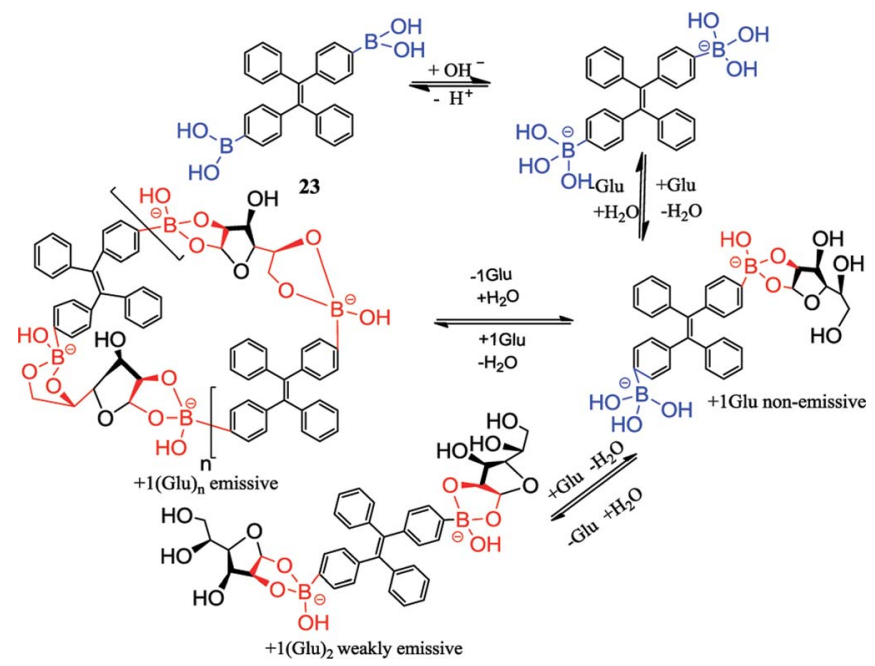

In another intriguing example, $\mathrm{Li}$ et al. recently reported a similar glucose fluorescent sensor 24 (TPEA + BAP) with the same response mechanism but a different method to induce aggregation, as depicted in Fig. $3 .^{72}$ Negatively charge of phenylboronic acid-containing polymer (BAP) induced positively charged tetraphenylethylene (TPEA) aggregation by electrostatic interaction, thus aryl rotor intramolecular rotation was limited, and the excited state released fluorescence through the radiation decay. Subsequently, after adding glucose and glucose oxidase, there was the formation of $\mathrm{H}_{2} \mathrm{O}_{2}$ that would react with PBA and then formed a weak acid phenol, thereby reducing the negatively charge on the BAP, resulting in disaggregation of TPEA. The limited internal rotation was liberated, and radiation decay transferred to non-radiation decay, resulting in fluorescence intensity weakening. Simultaneously, the team found that sensor $\mathbf{2 4}$ has small fluorescence changes when added D-fructose, D-galactose, and D-mannose, and then they successfully used sensor $\mathbf{2 4}$ to detect glucose in human serum. This is the first fluorescent sensor based on the difference in acidity between PBA and phenol, which brings a new concept for the study of glucose fluorescent sensors.

\subsection{Ribose boronic acid sensors (Table 4)}

Ribose can be used for the treatment of hepatitis B virus (HBV) and other diseases, the detection of ribose concentration in the body is very important. ${ }^{73}$ Zhang et al. synthesized a set of differently substituted diboronic acid sensor arrays (25), which achieved a discrimination of all tested five disaccharides and six monosaccharides by linear discriminant analysis (LDA). ${ }^{74}$ Fructose and ribose are the most selective in the binding selectivity of tested monosaccharides. The occurrence of different selectivity may be ascribed to the rigid and coplanar furanose form containing a pair of adjacent hydroxyl groups, which prefer to combine with boronic acid in order to minimize the angular strain. Moreover, the spatial orientation of the diol moiety largely regulates the combined process. This is the first time the IDA protocol involving diboronic acid sensors, providing new ideas for the development of sensors.

Lopez et al. described a new long-wavelength fluorescent sensor 26 containing a tricarbocyanine and boronic acid

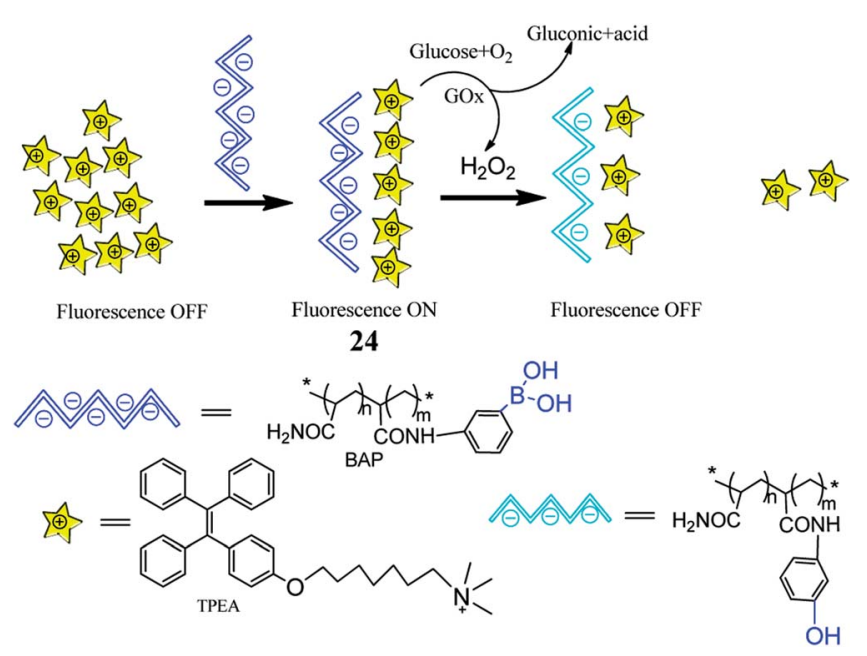

Fig. 3 Cartoon illustrating sensor 24 detecting glucose..$^{22}$ 
Table 4 Key information of ribose boronic acid sensors

\begin{tabular}{|c|c|c|c|c|c|}
\hline Sensor & Structure & & $\begin{array}{l}\text { Spectroscopic properties } \\
\left(\lambda_{\mathrm{ex}} ; \lambda_{\mathrm{em}}\right)\end{array}$ & $C$ (LOD; range $)$ & Functions and applications \\
\hline $25^{74}$ & & $\begin{array}{l}25 \mathrm{a}=\text { ortho } \\
25 \mathbf{b}=\text { meta } \\
25 \mathbf{c}=\text { para }\end{array}$ & $440 \mathrm{~nm} ; 528 \mathrm{~nm}$ & $-; 1 \mathrm{mmol} \mathrm{L}^{-1}$ & $\begin{array}{l}\text { Ribose: } K_{\text {ortho }}\left(213 \pm 15 \mathrm{~L} \mathrm{~mol}^{-1}\right), K_{\text {meta }} \\
\left(122 \pm 4 \mathrm{~L} \mathrm{~mol}^{-1}\right), K_{\text {para }}\left(93 \pm 4 \mathrm{~L} \mathrm{~mol}^{-1}\right) \\
\text { providing IDA protocol for diboronic acid sensors }\end{array}$ \\
\hline $26^{75}$ & & & $637,720 \mathrm{~nm} ; 820 \mathrm{~nm}$ & $300 \mathrm{nmol} \mathrm{L}^{-1} ;-$ & $\begin{array}{l}\text { Displaying selectivity toward ribose in the } \mathrm{pH} \\
\text { range of } 7.8 \text { to } 8.3 \text {; well-suited for detecting glycan } \\
\text { abundance in cells or tissues }\end{array}$ \\
\hline
\end{tabular}

structure. ${ }^{75}$ By adjusting the $\mathrm{pH}$ of the medium, this sensor can selectively recognize different kinds of carbohydrates. In one typical example, sensor 26 can selectively recognize ribose and fructose in the $\mathrm{pH}$ range of 7.8 to 8.3. Interestingly, this sensor has the longest fluorescent emission reported upon carbohydrates interaction. After excited at $720 \mathrm{~nm}$ or $637 \mathrm{~nm}$, it has a maximum at $820 \mathrm{~nm}$. Due to a sensitive signal in aqueous media and avoiding the use of co-solvents, sensor 26 can yield a true fluorescent response. Therefore, this sensor is well-suited for detecting glycan abundance in cells or tissues as well as other bioanalytical applications.

\subsection{Sialic acid boronic acid sensors (Table 5)}

Cell surface glycoprotein is composed of sugar and protein, such as sialyl Lewis X, sialyl Lewis A, etc. closely correlated with the development of tumor cells. These cell surface carbohydrates are normally regarded as markers of tumor cells. ${ }^{24}$ Borate compounds can bind to tumor cells and visualize them via fluorescence. A sensor (such as anthracene boronic acid sensors) prepared by linking two boronic acid groups with a peptide has highly selective to sialyl Lewis $\mathrm{X}$ and can be used to selectively label the surface of human hepatoma cells. ${ }^{76}$ Sialyl Lewis X is a kind of carbohydrates, which is not only considered a tumor cell marker but also as an antigen associated with the malignant behavior of tumor cells. ${ }^{77}$

In early 2002, Wang et al. reported the synthesis of an anthracene diboronic acid sensor 27 for sialyl Lewis X detection by an exquisite fabrication between diboronic acid groups. ${ }^{78}$ The sensor 27 has a strong affinity with sialyl Lewis $\mathrm{X}$ and is capable of selectively labeling sialyl Lewis X of HepG2 cells. Encouraged by the positive result, Wang et al. recently fabricated a novel fluorescent sensor 28 which is capable of selectively labeling the HEPG2 and HEP3B cell lines at low concentration $\left(1 \mu \mathrm{mol} \mathrm{L}^{-1}\right){ }^{79}$

Chu et al. developed boronolectin with high affinity and selectivity to recognize sialyl Lewis X, and fabricated sensor 29 by conjugated boronolectin with known fluorescent group BODIPY. In a further study, sensor 29 was successfully applied to fluorescence imaging of implanted tumor in mice. ${ }^{25}$ This work indicates that boronolectin can be used for selective imaging tumor in vivo.

Wang et al. synthesized four anthracene-based fluorescent diboronic acid sensors (30a-d) and examined the selectivity of different length linkers for sialyl Lewis. ${ }^{80}$ It was found that the fluorescence of 30a increased after binding to sialyl Lewis Y. The result indicates that 30a has a high sensitivity and selectivity for sialyl Lewis Y. Although all the diboronic acids 30a-d have very similar molecular structures, the different length linkers may affect the difference in the relative positions of the boronic acid groups, thereby causing different selectivity. Subsequently, Wang and co-worker evaluated the ability of 30a to selectively label sialyl Lewis Y-expressing cells and found that sensor 30a selectively stained HEP3B cells. To date, there are no sensitive and selective boronic acid-based sensors for sialyl Lewis $\mathrm{Y}$, therefore sensor 30a is a very valuable research tool and potential diagnostic agent.

Chang et al. synthesized three potential diboronic acid fluorescent sensors 31-33 to detect sialyl Lewis X, which bind to sialyl Lewis $\mathrm{X}$ antigens by PET mechanism. ${ }^{24}$ Wherein the sensor 33 exhibits the strongest fluorescence enhancement when combined with sialyl Lewis X. Moreover, it was confirmed non-toxic to the cells and well selective to detect sialyl Lewis X. This sensor holds great potential for the diagnosis of tumor cells.

Sialic acids are unusual carbohydrates that are widely expressed at the termini of glycan chains on the cell surface. In particular, compared to normal cells, it has a much higher expression level on the cancer cells surface. ${ }^{\mathbf{8 1 , 8 2}}$ Zhang et al. reported a novel method to analyze sialic acids on cancer cells surface via inductively coupled plasma mass spectrometry (ICPMS) ${ }^{41}$ Under physiological conditions ( $\mathrm{pH} 7.4$ ), biotinylated 3aminophenylboronic acid (biotin-APBA) 34 selectively recognizes sialic acids. Based on this property, gold nanoparticles (AuNPs) can significantly enhance the biotin-APBA signal in ICP-MS when AuNP are used as labeled elements biotin-APBA, as depicted in Fig. 4. The result demonstrated that the 
Table 5 Key information of sialic acid boronic acid sensors

-

Sensor Structure

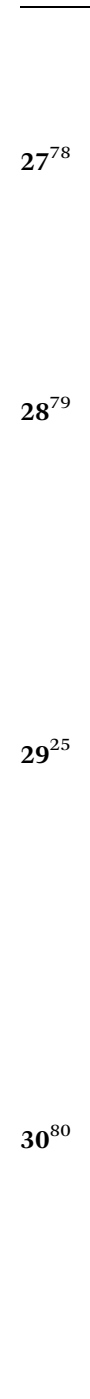

$31^{24}$<smiles>CN(Cc1ccccc1B(O)O)Cc1c2ccccc2c(CN(C)C(=O)NCCN)c2ccccc12</smiles><smiles>CC(C)C(=O)N(C)Cc1c2ccccc2c(CN(C)Cc2ccccc2B(O)O)c2ccccc12</smiles>

$\mathrm{OH}$<smiles>OB(O)c1ccccc1CN(Cc1ccccc1B(O)O)Cc1cccc2cc3ccccc3c(CN(Cc3ccccc3B(O)O)C3CCCCC3)c12</smiles><smiles>CN(Cc1ccccc1B(O)O)c1ccc(/C=C/C2=CC(=C(C#N)C#N)C=C(/C=C/c3ccc(C(C#N)Cc4ccccc4B(O)O)cc3)O2)cc1</smiles><smiles>CNc1ccc(/C=C/C2=CC(=C(C#N)C#N)C=C(/C=C/c3ccc(C(C#N)Cc4ccccc4B(O)O)cc3)O2)cc1</smiles><smiles>CC1=CC(=C(C#N)C#N)C=C(C=Cc2ccc(C(C#N)Cc3ccccc3BO)cc2)O1</smiles>

$367 \mathrm{~nm}$;

$415 \mathrm{~nm}$

$651 \mathrm{~nm}$ $660 \mathrm{~nm}$

Spectroscopic properties

$\left(\lambda_{\mathrm{ex}} ; \lambda_{\mathrm{em}}\right)$

$C$ (LOD; range)

Functions and applications
$370 \mathrm{~nm}$;

$426 \mathrm{~nm}$

-; $60 \mu \mathrm{mol} \mathrm{L}^{-1}$

-; $60 \mu \mathrm{mol} \mathrm{L}^{-1}$
Fluorescence intensity enhancement (nearly 40\%); binding with sialyl Lewis X, labeling sialyl Lewis X of HepG2 cells

Fluorescence intensity $\uparrow$; binding with sialyl Lewis X, staining HepG2 and HEP3B liver carcinoma cells

The intensity of tumor (95 \pm 12$)$; binding with sialyl Lewis $\mathrm{X}$, imaging of implanted tumor in mice
Fluorescence intensity enhancement $375 \mathrm{~nm} ;$
$424 \mathrm{~nm}$ $400 \mathrm{~nm}$; $617 \mathrm{~nm}$

$400 \mathrm{~nm}$; $614 \mathrm{~nm}$

$400 \mathrm{~nm}$; $607 \mathrm{~nm}$
-; 0.1 to $20 \mu \mathrm{mol} \mathrm{L}^{-}$

$89 \%$ yield, > 2 -fold $\left(1 \mu \mathrm{mol} \mathrm{L}{ }^{-1}\right)$;

binding with sialyl Lewis $\mathrm{X}$, showed close integration with hepatoma B cell-line PLC/PRF/5, with HepG2

$82 \%$ yield, $\uparrow 3$-fold $\left(0.10 \mu \mathrm{mol} \mathrm{L}^{-1}\right)$; binding with sialyl Lewis $\mathrm{X}$, showed specific integration with PLC/PRF/5 and with HepG2 
proposed method is highly selective to tumor cells. HepG2 cells and MCF-7 cells were used as two tumor models to evaluate the expression level of sialic acid on the cancer cells surface. The mean numbers of sialic acid expression on MCF-7 cells and HepG2 cells were $7.0 \times 10^{9}$ and $5.4 \times 10^{9}$, respectively. For systematic extension of the research, the numbers of HepG2 and MCF-7 cells were 120 and 64, respectively under the limits of detection. The relative standard deviations were $9.6 \%$ and $8.9 \%$, respectively. And the linear ranges for HepG2 cell and MCF-7 cell were 300-1000 and 170-11 000, respectively. This method can be applied to analyze sialic acid on the tumor cells surface, which is favorable to diagnose cancer according to tumor markers. ${ }^{83}$

\subsection{Glucosamine boronic acid sensors}

Although pharmacokinetics and pharmacodynamics of glucosamine are unclear, glucosamine is one of the most popular nonprescription nutritional products on the market that is used to treat osteoarthritis. However, reports related glucosamine on the treatment of diseases are various, such as rheumatoid arthritis, gastric ulcer and hepatitis. ${ }^{84}$ The concentration of glucosamine in normal living cells is between 1 and $2 \mathrm{mmol}$ $\mathrm{L}^{-1}$, but it can reach $10 \mathrm{mmol} \mathrm{L}^{-1}$ if oral administration. High concentrations of glucosamine or its derivatives can inhibit certain tumor cells. ${ }^{85}$ Those findings are favorable in developing new drugs for the treatment of cancer, thus the detection of glucosamine is particularly important. Tam Minh Tran et al. reported a novel sensor $\mathbf{3 5}$ for glucosamine. ${ }^{\mathbf{4 2}}$ Based on a boronic acid-containing coumarin aldehyde, the sensor 35 has a smaller binding chamber. Due to form a boronic ester and an iminium ion, it exhibits an excellent selectivity for glucosamine. The aldehyde group of the sensor $\mathbf{3 5}$ can be reversibly bound to the primary amine to form an ammonium ion, and the ammonium ion enhances the ICT of the coumarin, resulting in a large red shift of the excitation spectrum. When added glucosamine at therapeutic concentration and excited at $488 \mathrm{~nm}$, sensor emission increased and moved from $520 \mathrm{~nm}$ to $568 \mathrm{~nm}$. The sensor has a higher fluorescence intensity and binding affinity towards glucosamine than other similar biomolecules. Compared to simple amino acids, the binding constant $\left(K_{\mathrm{a}}=4100 \mathrm{~L} \mathrm{~mol}^{-1}\right)$ was nearly two orders of magnitude higher. The study offered a new concept for the fabrication

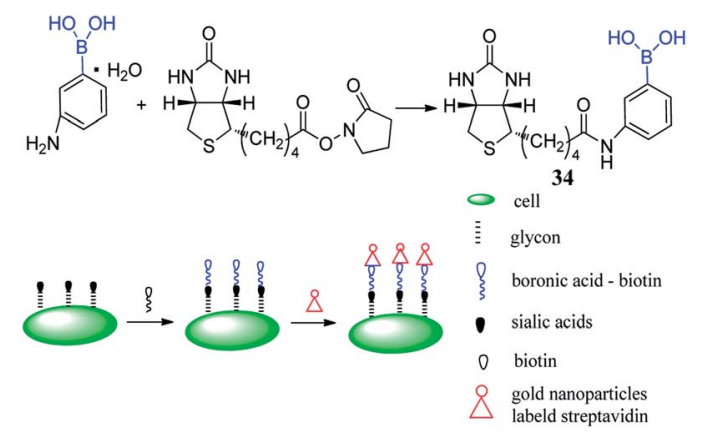

Fig. 4 Cartoon illustrating sensor 34 combining with AuNPs. ${ }^{41}$ of a highly selective open optical sensor that selectively detects multifunctional biomolecules.
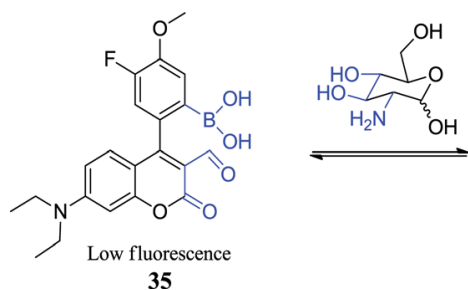

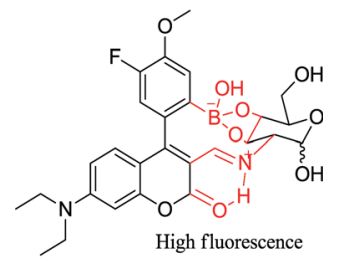

\section{6. $\alpha$-hydroxy carboxylate boronic acid sensors}

Lactate is a biologically important $\alpha$-hydroxy carboxylate formed by the red blood cells, and its abnormally high content $(>6.5$ $\mathrm{mM}$ ) is associated with sepsis, trauma and other severe diseases. Therefore, monitoring lactate content is an important significance for intensive care unit diagnosis and prevention of diseases. Hansen et al. reported that BODIPY-based boronic acid pinacolate derivatives sensors $\mathbf{3 6}$ a and $\mathbf{3 6 \mathbf { b }}$ act as high lactate selectivity detectors at physiological $\mathrm{pH}(7.4) .{ }^{43}$ Interestingly, some biologically important monosaccharides (D-glucose, D-fructose, and D-mannose) were found to have no response to sensors 36a and $\mathbf{3 6 \mathbf { b }}$. The potentially interfering substances (L-malate, vitamin C) are often overlooked because their concentrations are constant and low in the body. Sensors 36a and 36b have absorption maxima at $612 \mathrm{~nm}$ and $613 \mathrm{~nm}$ respectively, and their respective absorption spectra are the same as their excitation spectra. As the DL-lactate concentration is increased, sensors $\mathbf{3 6 \mathbf { a }}$ and $\mathbf{3 6 \mathbf { b }}$ exhibit a significant increase in excitation and emission intensity. This phenomenon may be ascribed to the fact that the electrons are less likely to be accepted by the arylboronate unit, resulting in the oxidative quenching of the BODIPY core upon arylboronate formation decreasing.

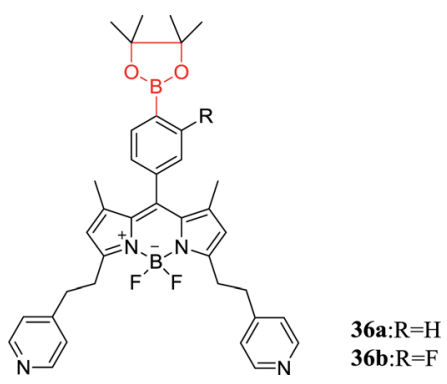

Owing to most pharmaceutical agents requires asymmetric synthesis in the progress of discovery and production, the fabrication of available analytical tools for the recognition of the enantio-composition of reaction products plays a key role. $\mathrm{Wu}$ et al. fabricated chirality sensors 37 and 38 for $\alpha$-hydroxy carboxylates by linked boronic acid groups to a perylene bisimide (PBI) chromophore and induced helical aggregation of achiral PBI. ${ }^{86}$ PBI chromophore functionalized with boronic acid moieties is shown to be efficient chirality sensors for $\alpha$-hydroxy carboxylates. The aggregates displayed induced circular dichroism (CD) signals from the PBI chromophore and indicated 
the $e e$ of the analytes. In a further study, they combined sensor 37 with an aldehyde-functionalised PBI sensor 39 for sensing of $\mathrm{L}^{-}$ DOPA.$^{87}$ As a result, owing to aggregation made the boronic acid and aldehyde groups form two dynamic covalent bonds, the two sensor components showed to be efficient binding to L-DOPA.

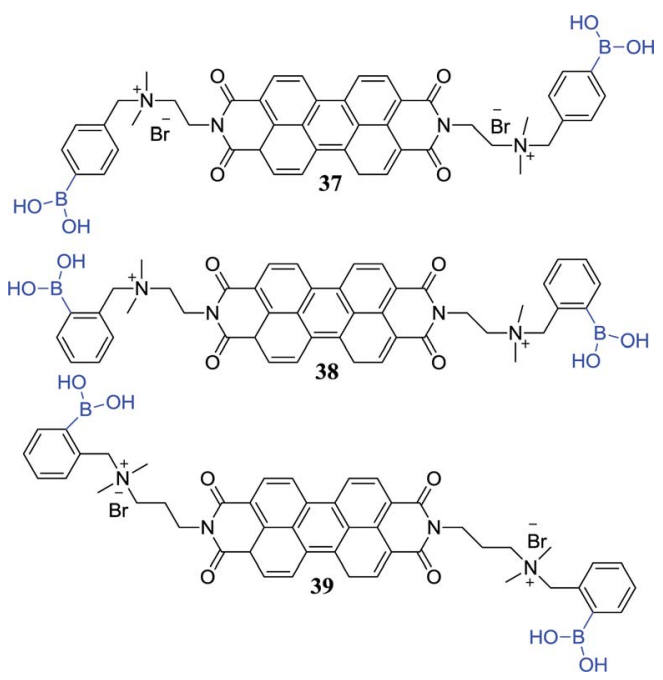

\subsection{ATP boronic acid sensors}

Adenosine triphosphate (ATP) mainly provides energy for cells and plays an important role in the activation of neuronal transmission, ${ }^{88}$ ion channel. ${ }^{89}$ The development of sensors that effectively detect intracellular ATP concentrations is important for the study of human metabolic activity and the monitoring of health levels. ${ }^{90}$ Wang et al. reported sensor 40 that has good biocompatibility and membrane permeation can rapidly detect intracellular ATP. ${ }^{44}$ There were three aspects facilitating the formation of ring-opening structure and produce strong fluorescence. First, the boronic acid group combined with the ribose moiety of ATP via the reversible covalent bond and forms boronic acid esters. Second, the $\pi-\pi$ stack was formed by xanthane and adenine. Third, there was the electrostatic interaction between the amino group and the phosphoric acid ester group. Sensor $\mathbf{4 0}$ is effective in response to ATP at a concentration of $10 \mu \mathrm{mol} \mathrm{L}^{-1}$, while has no significant fluorescence changes with other biomolecules such as carbohydrates, metal ions, etc. The team cultured cells with high levels of ATP by using camptothecin-induced apoptosis, and then sensed them with fluorescent sensor 40. The results showed that camptothecin-treated cells were clearly stained, while the untreated control group was not stained. The sensor can effectively monitor intracellular ATP levels in real time and provides an effective strategy for the development of such sensors.

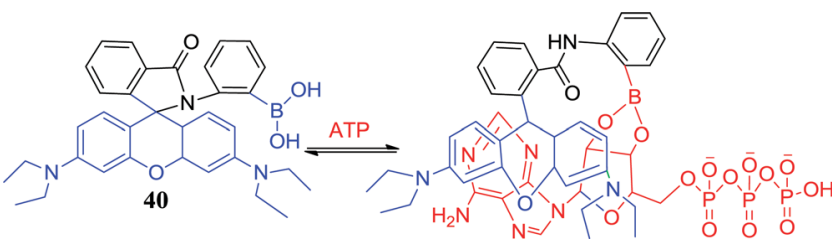

Jiang et al. reported that gold nanoparticles (AuNPs) coated with 4-mercaptophenylboronic acid (MPBA) can be used for the determination of ATP, as depicted in Fig. 5. ${ }^{45}$ Interestingly, the treated AuNPs are easily polymerized to form a boroxine ring, and its color changes from red to blue. However, in the presence of ATP, a stable borate ester is formed by the boronic acid group of the MPBA preferentially binding the 2,3-hydroxyl group of ATP. At the same time, the polymer dissolves and its color is reversed. In addition, AuNPs-based colorimetric assays successfully detected ATP levels in human breast cancer and in samples treated with antineoplastic drugs. Due to their low cost, easy preparation and the ability to perform bare eyes observation, colorimetric assays offer a potential new strategy for the early diagnosis of cancer.

\subsection{Amyloid- $\beta$ plaques boronic acid sensors}

Amyloid- $\beta$ (A $\beta$ ) plaques are mainly composed of the amyloid$\beta$ peptide, which is a key pathological feature of $\mathrm{AD} .{ }^{91}$ Thus, the detection of $A \beta$ plaques can be used to monitor the potential for $\mathrm{AD}$ progression in vitro and in vivo. ${ }^{92}$ Recently, the interest in the research of the $A \beta$ plaque dye has increased, such as Thioflavin T, ${ }^{93}$ DAPI, ${ }^{94}$ Congo red ${ }^{95}$ and so on. Jung et al. found that boronic acid has a good selectivity to $A \beta$ aggregation and fabricated a boronic acid fluorescent sensor 41c, which significantly increased the fluorescence intensity in response to $A \beta$ aggregation ( 64.37 fold, $F_{\mathrm{A} \beta} / F_{0}$ ), and the wavelength had a blue shift $(105 \mathrm{~nm}) .{ }^{46}$ They found that boronic acid as a functional group improved the binding affinity with the $\mathrm{A} \beta$ aggregates $\left(K_{\mathrm{D}}\right.$ value $=0.79 \pm 0.05 \mu \mathrm{mol} \mathrm{L} \mathrm{L}^{-1}$ for 41c) and confirmed that 41c selectively stained A $\beta$ plaques in brain slices of APP/PS1 mice. Using mice (normal and APP/PS1) for fluorescence imaging in vitro also showed that 41c is able to penetrate the blood-brain barrier (BBB) and stains the $\mathrm{A} \beta$-plaque in the brain. From these results, it showed that $41 \mathrm{c}$ will be useful as a fluorescent sensor in $\mathrm{AD}$ related preclinical studies and provides valuable information for the development of $\mathrm{A} \beta$-plaque sensors.

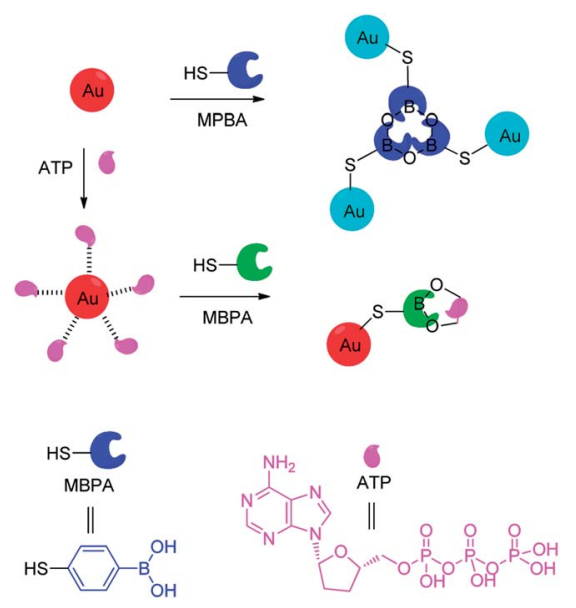

Fig. 5 Cartoon illustration of ATP detection via the AuNPs-based colorimetric assay. ${ }^{45}$ 


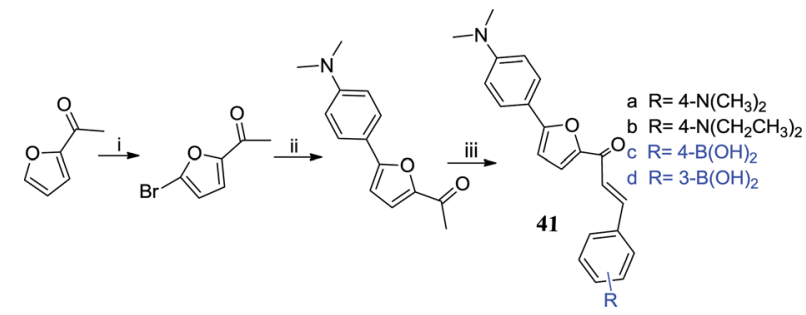

3. Catecholamines boronic acid sensors

Catecholamines are benzene derivatives with two neighboring (ortho-) hydroxyl groups, including adrenaline, norepinephrine and dopamine and their derivatives. ${ }^{96}$ Adrenaline and norepinephrine are not only hormones secreted by the adrenal medulla, but also the neurotransmitters of the norepinephrine fibers in the central nervous system and the sympathetic nervous system. Adrenaline has low content in the central nervous system, while norepinephrine is widely present in the central nervous system and its content is more abundant. Dopamine is present in the vertebral body as a nerve medium. Catecholamines that contain a strong biological activity of endogenous substances in the brain are important adrenergic receptor agonists and play an important role in various nerve signal transmissions. The content of catecholamines in the organism is closely related to the physiological and pathological phenomena of the human body. Catecholamines not only regulate the metabolism in the body, but also affect the kidney, cardiovascular system, nervous system, endocrine system and other normal physiological activities. ${ }^{97}$ The detection of catecholamines in the human body contributes to the diagnosis of renal insufficiency, thyroid dysfunction, diabetes mellitus, congestive heart failure and other diseases, and some tumor cells can lead to metabolic abnormalities of catecholamines in the body, such as some pheochromocytoma, neuroblastoma, paraganglioma.

In a further study of catecholamines, the analytical methods are increasingly diversified. It is important to choose a high selectivity and sensitivity method for catecholamines. Up until now, the main analytical methods are based on highperformance liquid chromatography (HPLC). It is less application via combining capillary electrophoresis with fluorescence spectrophotometry or combining electrochemical analysis with liquid chromatography as analytical methods. ${ }^{98}$ Catecholamines are chemically characterized by a dihydroxybenzene nucleus and a side chain with amino groups. In the biological sample, the content of catecholamines is very low. Furthermore, catecholamines have extremely poor stability and are easily oxidized. In addition, it is difficult to accurately determine the concentration of catecholamines in the biological sample by adding various endogenous chemical disruptors. High selectivity and sensitivity in the determination of catecholamines in biological samples such as the precise determination of serum norepinephrine or adrenaline are currently required to achieve the clinical goal, thus the development of a simple operation,

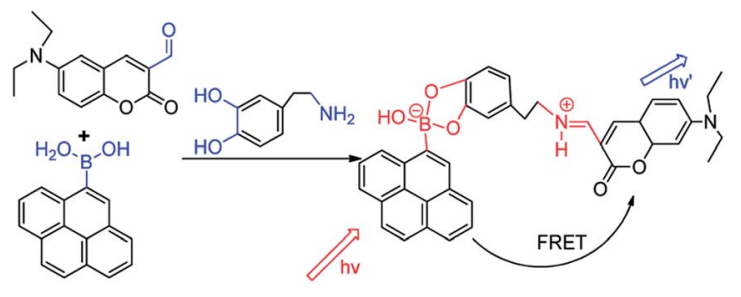

Fig. 6 Catecholamine detection diagram. ${ }^{23}$

cheap and highly sensitive detection methods is imperative. In recent years, the use of fluorescent methods to detect catecholamines is various, wherein boronic acid fluorescent sensors have been widely concerned. ${ }^{99,100}$ Aromatic cis-diols or catechol derivatives interact with boronic acid and form reversible cyclic esters. In one typical example, Chaicham et al. reported a FRETbased detection system contained two different fluorescent sensors and an appropriate catecholamine acting as a guest linker, as depicted in Fig. 6. Catecholamine can interact with boronic acid and aldehyde, inducing the FRET mechanism to recognize the effectively structural similarity of catecholamines. ${ }^{23}$

In another intriguing example, Jun et al. fabricated a fluorescent sensor $\mathbf{4 2}$ which is used to detect catecholamines, such as dopamine, dopa, and 3,4-dihydroxyphenylacetic acid (DOPAC). ${ }^{101}$ They found that DOPAC shows the largest association constant with sensor $\mathbf{4 2}$ and displays fluorescence quenching effects, while D-fructose, D-glucose, and phenylalanine have no remarkable fluorescence change. In addition, they carefully explained the unique intermolecular excimer formation and fluorescence quenching effects with DOPAC and catechols based on the theoretical calculations. Ptak et al. investigated the interaction of PBA with noradrenaline, dopamine, L-DOPA, DOPA-P and catechol via potentiometry and NMR spectroscopy, respectively. For comparison, they fabricated sensor $\mathbf{4 3}$ and did the same test. They found that PBA has a high affinity to noradrenaline, while sensor $\mathbf{4 3}$ shows promising ability to bind dopamine. ${ }^{102}$

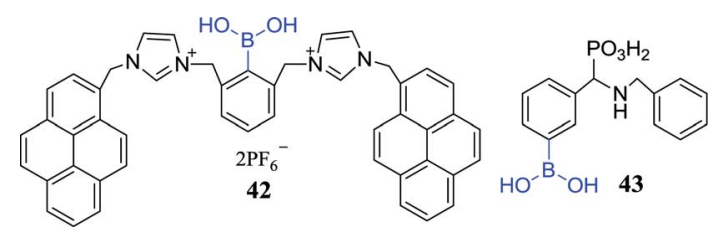

Devi et al. reported a fluorescent sensor 44 (Au-BSA-APBA) that amino phenyl boronic acid (APBA) conjugated to gold nanocluster (Au-BSA NCs) can apply to detect dopamine, ${ }^{103}$ as depicted in Fig. 7. It took advantage of the combination of lactose and fluorescent sensors resulting in fluorescence quenching, and then dopamine was competitively substituted for lactose resulting fluorescence opening. Compared to glucose and galactose, the lactose molecule has two sets of cis-diols groups, showing the highest sensitivity to the Au-BSA-APBA sensor with a detection limit as low as $0.02 \mu \mathrm{mol} \mathrm{L}^{-1}$. Due to the sensor has a greater affinity to dopamine, it is easier to form 


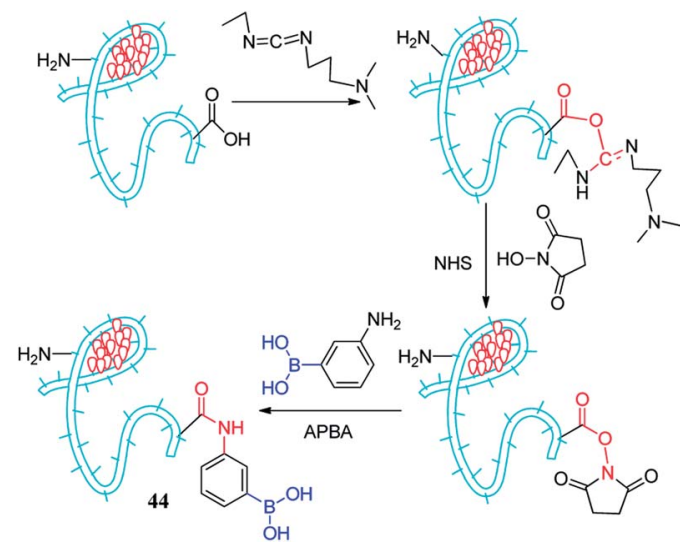

Fig. 7 Formation of boronic acid conjugated gold nanoclusters (sensor 44). ${ }^{103}$

a stable complex. With the increase of dopamine concentration, lactose was gradually replaced, aggregates ruptured and restored fluorescence with a detection limit of $0.7 \mu \mathrm{mol} \mathrm{L}{ }^{-1}$. The team found that the Au-BSA-APBA-lactose conjugate has a specific fluorescence response in the presence of catecholamines such as adrenaline and norepinephrine. They also carried out the effects of interfering analytes including ascorbic acid, uric acid, arginine, histidine, and lysine. It was gratifying that the Au-BSA-APBA-lactose conjugate maintains the specificity and sensitivity to dopamine. Due to the green dual mode turn-off - turn-on nano-sensor and the simple method and low consumption time, the Au-BSA-APBA sensor has a great prospect in the future medical diagnosis and treatment.

\section{Reactive species boronic acid sensors}

Reactive oxygen species (ROS) are generally referred to a class of substances that contain active oxygen atoms in the body. It mainly includes superoxide anion radical $\left(\mathrm{O}^{2-}\right), \mathrm{H}_{2} \mathrm{O}_{2}$, hydroxyl radical $\left(\mathrm{HO}^{-}\right)$, hypochlorite $\left(\mathrm{ClO}^{-}\right)$, etc. It has been found that peroxides on the regulation of a variety of physiological activities in the cell are indispensable, such as activation of immune cells, immune response, signal transduction, and so on. ${ }^{104}$ In addition, ROS are also associated with a number of diseases, such as cancer and Alzheimer's disease, neurodegenerative Parkinson's disease. ${ }^{105}$ Therefore, the timely and accurate detection of the concentration of ROS in the body is very valuable in the prevention of disease, diagnosis, and treatment. However, due to the strong reactivity of active oxygen and poor stability, it is extremely important to develop sensors with high selectivity for ROS.

\subsection{Hydrogen peroxide boronic acid sensors (Table 6)}

As one of the most important biological ROS, $\mathrm{H}_{2} \mathrm{O}_{2}$ is associated with immune system function and considered as the function of healthy physiological signaling pathways such as cell proliferation, differentiation and migration. Therefore, it is important to detect $\mathrm{H}_{2} \mathrm{O}_{2}$ in vivo. ${ }^{21}$ The use of fluorescent sensors can be achieved "real-time, visible, quantitative" detection of $\mathrm{H}_{2} \mathrm{O}_{2}$ in living cells and tissues by means of laser confocal imaging technology. This provides an important approach for demonstrating the role of $\mathrm{H}_{2} \mathrm{O}_{2}$ in the physiological and pathological process.

4.1.1. Hydrogen peroxide boronic acid sensors directly connected to a fluorophore. Borate or boronic acid groups can quench the fluorescence of fluorophore, thus the sensor itself does not emit fluorescence or emits weak fluorescence. When the borate reacts with $\mathrm{H}_{2} \mathrm{O}_{2}$, the sensor can be hydrolyzed to hydroxy and releases fluorescence, as depicted in Fig. 8. There are many compounds that act as fluorophores, such as coumarins, fluoresceins, tricyclics, and merocyanine. Among them, Wang et al. reported a water-soluble coumarin-based borate fluorescent sensor 45 with high selectivity to $\mathrm{H}_{2} \mathrm{O}_{2} \cdot{ }^{22}$ The sensor excitation wavelength was shorter $(332 \mathrm{~nm})$, but it could easily cause damage to the body in the cell or biological imaging. Subsequently, the team had been modified the sensor by introduced triazole to extend its conjugated system and fabricated sensor $46 .{ }^{106}$ Interestingly, its excitation wavelength was red shifted $70 \mathrm{~nm}$, and was more suitable for imaging in cells and organisms.

Merocyanine is a heterocyclic compound consisting of an electron withdrawing group and an electron donating group such as a phenol group. When the electron donor group is converted from phenol to phenol salts, ICT mechanism will be significantly improved. Zhan et al. reported a boron-based merocyanine sensor $47 .{ }^{107}$ When $\mathrm{H}_{2} \mathrm{O}_{2}$ was present, the borate of sensor $\mathbf{4 7}$ was oxidized and hydrolyzed to hydroxyl, and the merocyanine dye was released. The process remarkably changed from colorless $\left(\lambda_{\max }=391 \mathrm{~nm}\right)$ to dark red $\left(\lambda_{\max }=522\right.$ $\mathrm{nm})$. The absorption peak of the merocyanine dye in its acidic form was at $420 \mathrm{~nm}$, while the absorption peak in its alkaline form was at $522 \mathrm{~nm}$. The sensor absorption was linear with the concentration of $\mathrm{H}_{2} \mathrm{O}_{2}$ in the range of $1.0 \times 10^{-7} \mathrm{~mol} \mathrm{~L}^{-1}$ to 2.5 $\times 10^{-5} \mathrm{~mol} \mathrm{~L}^{-1}$ with the detection limit of $6.8 \times 10^{-8} \mathrm{~mol} \mathrm{~L}^{-1}$ under optimum conditions. Subsequently, they found that foreign substances had litter influence on the sensor. In summary, the sensor is successfully applied to detect hydrogen peroxide in rainwater in a buffer solution of $\mathrm{pH}$ 9. The unique performance of merocyanine dye makes it possible to be a promising structural scaffold for fabricating sensors.

Lampard et al. reported on a series of $\mathrm{H}_{2} \mathrm{O}_{2}$ boronate fluorescent sensors. ${ }^{108} \mathbf{4 8 a}$ and $48 \mathrm{~b}$ showed fluorescent responses towards $\mathrm{H}_{2} \mathrm{O}_{2}$, which may be ascribed to the loss of ICT excited state. Whereas, due to the introduction of ICT excited state, the fluorescence intensity of $\mathbf{4 8 c}$ and $\mathbf{4 8 d}$ decreased in the presence of $\mathrm{H}_{2} \mathrm{O}_{2}$. This shows the importance of electron-withdrawing or electron-donating groups in these systems. Based on the above principles, the research team synthesized two $\mathrm{H}_{2} \mathrm{O}_{2}$ sensors (49 and 50) by using the same steps. Unfortunately, the extended conjugation between boronic acid and dimethylamino in $\mathbf{4 9}$ resulted in a fluorescence response similar to that of $\mathbf{4 8 c}$, whereas the fluorescence of $\mathbf{5 0}$, although increased 3.6-fold, could not be applied to detection of $\mathrm{H}_{2} \mathrm{O}_{2}$ with cell imaging experiments because of poor sensitivity. Nonetheless, these 
Table 6 Key information of hydrogen peroxide boronic acid sensors

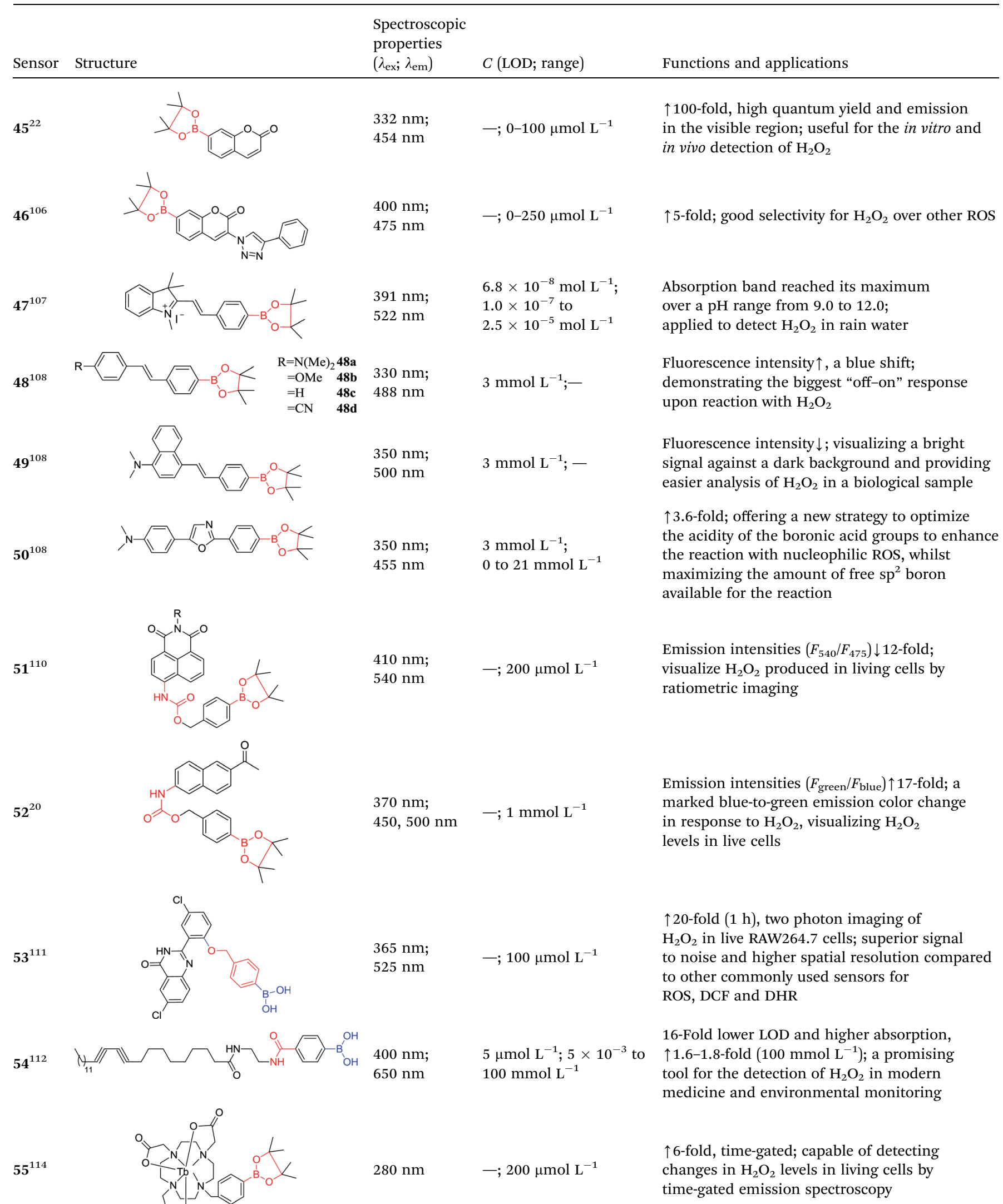




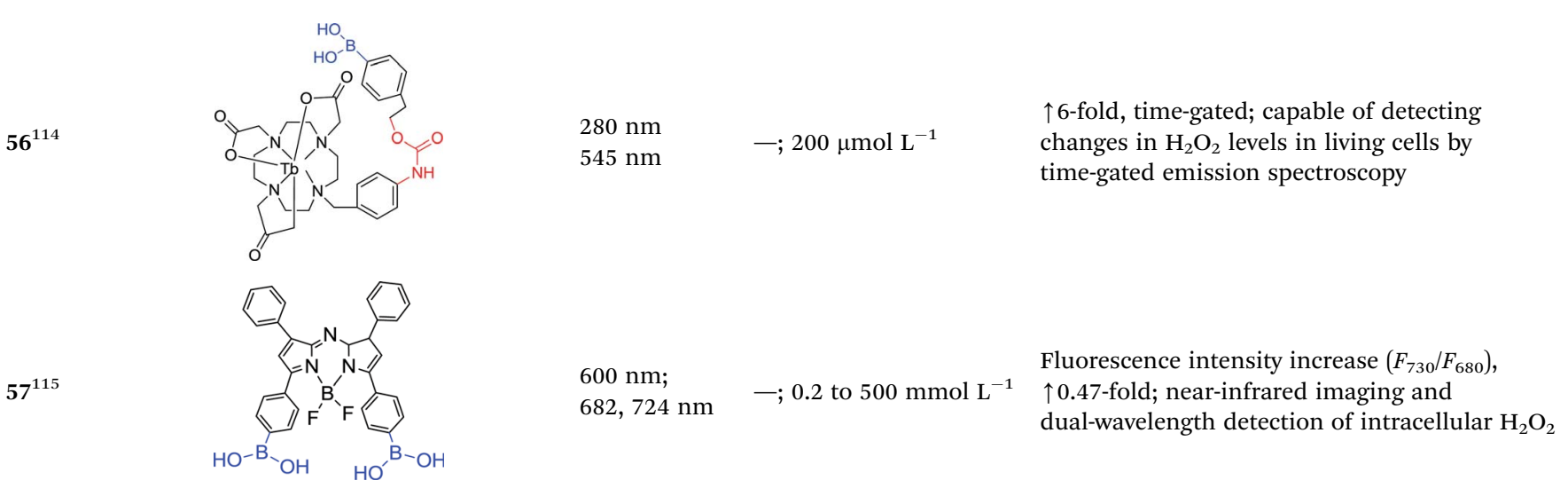

studies are very useful for the development of a series of ICT fluorescent sensors that enhance sensitivity to $\mathrm{H}_{2} \mathrm{O}_{2}$.

4.1.2. Hydrogen peroxide boronic acid sensors with broken linker. The researchers connected the borate with the benzyloxycarbonyl group and formed a novel fluorescent sensor. When it encounters $\mathrm{H}_{2} \mathrm{O}_{2}$, the borate is converted to a hydroxyl group, causing the cleavage of the benzyloxycarbonyl group and releasing the fluorophore. ${ }^{109}$ Based on a similar mechanism, Chang et al. fabricated two-photon fluorescent sensor $\mathbf{5 1}^{\mathbf{1 1 0}}$ and $\mathbf{5 2},{ }^{20}$ which have good selectivity for $\mathrm{H}_{2} \mathrm{O}_{2}$ while imaging $\mathrm{H}_{2} \mathrm{O}_{2}$ produced in living cells. Two-photon confocal microscopy showed that sensor $\mathbf{5 1}$ is able to detect $\mathrm{H}_{2} \mathrm{O}_{2}$ produced during the cellular immune response. Sensor $\mathbf{5 2}$ has good light stability and negligible toxicity, which can observe the distribution of $\mathrm{H}_{2} \mathrm{O}_{2}$ in cells and tissues.

Lindberg et al. reported $\mathrm{H}_{2} \mathrm{O}_{2}$ sensor 53 using a quinazolinone precipitating dye (QPD) connected to a boronic acid-based immolative linker. ${ }^{111}$ QPD is highly photostable and capable of highly localizable fluorescent signals in cells. Synthetic $\mathrm{B}(\mathrm{OH})_{2}{ }^{-}$ QPD, in the presence of $\mathrm{H}_{2} \mathrm{O}_{2}$, yields the para-benzyl hydroxyl and QPD, causing a strong fluorescence precipitate. In addition, in the live cell experiments performed, bright fluorescence precipitates were observed, demonstrating a selective response to hydrogen peroxide in a cellular context and enabling the visualization of endogenous hydrogen peroxide in phagosomes.

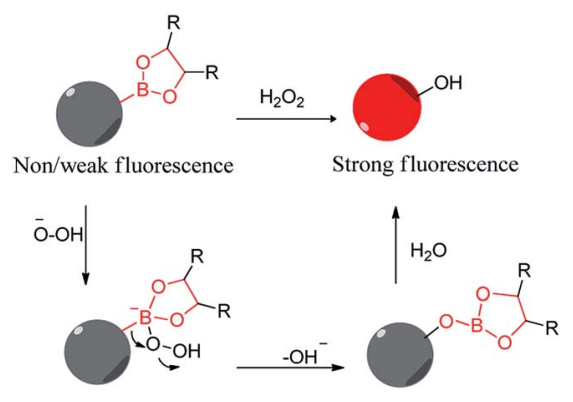

Fig. $8 \quad \mathrm{H}_{2} \mathrm{O}_{2}$ detection diagram.
Jia et al. reported a new optical sensing method for detecting $\mathrm{H}_{2} \mathrm{O}_{2}$, which introduced phenylboronic acid groups can effectively enhance the response of polydiacetylene vesicles to $\mathrm{H}_{2} \mathrm{O}_{2} \cdot{ }^{112}$ Sensor 54 has maximum absorption at $650 \mathrm{~nm}$. It has a good linear relationship in the concentration range from $5 \times$ $10^{-3}$ to $100 \mathrm{mmol} \mathrm{L}^{-1}$, and $R^{2}$ reaches 0.991 . The detection limit is $5 \mu \mathrm{mol} \mathrm{L}{ }^{-1}$.

4.1.3. Other types of hydrogen peroxide boronic acid sensors. Rare earth luminescence sensors have the advantages of large stokes shift and narrow emission range, thus they can reduce the interference of background fluorescence and can be applied to the field of biological detection. ${ }^{\mathbf{1 1 3}}$ However, the molar extinction coefficient of the rare earth compound is relatively low, and the organic ligand needs to be sensitized by energy transfer. Based on this mechanism, Chang et al. fabricated two lanthanide-based luminescent sensors 55 and $56 .^{114}$ The electron-withdrawing boronic acid group on the aromatic ring sensitized the rare earth compound by hydrolyzed to a phenolic hydroxyl group or an amino group in the presence of $\mathrm{H}_{2} \mathrm{O}_{2}$, and then the sensors generated fluorescence.

$\mathrm{Xu}$ et al. reported that borate-functionalized azaborinemethylene dyes 57 showed changes in intracellular $\mathrm{H}_{2} \mathrm{O}_{2}$ during biological processes, as depicted in Fig. 9. ${ }^{115}$ This is a designed sensor for near-infrared imaging and dual-wavelength detection. Due to proper cell permeability and long excitation and emission wavelengths, it can avoid autofluorescence from natural cell interference. Moreover, the selectivity of the boronic acid group to react with hydrogen peroxide is higher than other ROS.

\subsection{Peroxynitrite boronic acid sensors}

Peroxynitrite $\left(\mathrm{ONOO}^{-}\right)$is a highly active oxidant and an effective nitrating agent in physiological and pathological processes, which is formed by nitric oxide (NO) and $\mathrm{O}^{2-} \cdot{ }^{116}$ The use of simple and rapid methods for the effective and applicable detection of $\mathrm{ONOO}^{-}$is increasingly significant. Han et al. synthesized a fluorescent borate-based sensor $\mathbf{5 8}$ for rapid 


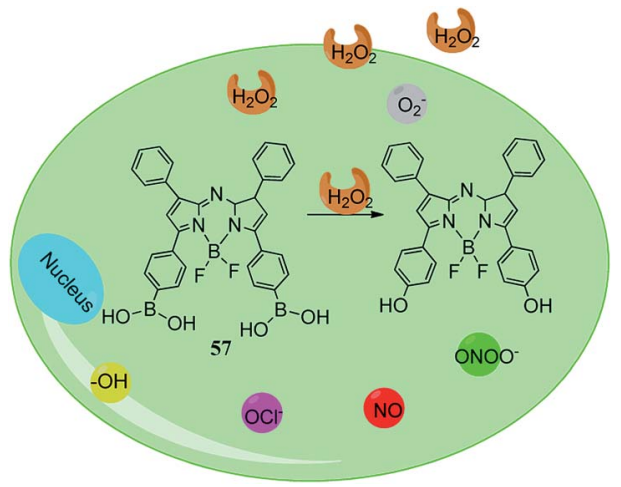

Fig. 9 Cartoon illustration of intracellular hydrogen peroxide using sensor $56 .{ }^{115}$

detection of $\mathrm{ONOO}^{-}$by a reaction-based indicator displacement assay (RIA). ${ }^{117}$ The fluorescent sensor KB7 was based on the effective coupling between DCM and the boronic acid moiety. DCM dye had a long excitation and emission wavelength ${ }^{\mathbf{1 1 8}}$ and the boronic acid moiety was acted as a saccharide receptor. ${ }^{119}$ The boronic acid moiety interacted rapidly with lactulose in an aqueous media and formed a fluorescent KB7-lactose complex (sensor 58) that exhibits higher sensitivity and better selectivity for $\mathrm{ONOO}^{-}$than other tested substances. The introduction of the glycosyl group not only improved the water solubility and biocompatibility of KB7-lactose complex, but also protected the boronic acid from oxidation by other oxidants. This might be ascribed to the mechanism that $\mathrm{ONOO}^{-}$attacked aromatic carbon adjacent to the boron atom, resulting in partial cracking of the boronic acid. The sensor of KB7 $\left(20 \mu \mathrm{mol} \mathrm{L}{ }^{-1}\right)$-lactulose $\left(100 \mathrm{mmol} \mathrm{L}^{-1}\right)$ can penetrate into viable cells and show strong fluorescence throughout the cytoplasm. Sensor $\mathbf{5 8}$ can be used for visualization of $\mathrm{ONOO}^{-}$. Subsequently, cytotoxicity tests conducted by the team showed non-toxic. Compared to other competitive ROS or nitrogen species (RNS), the sensor exhibits better selectivity for $\mathrm{ONOO}^{-}$and is more useful for measuring trace amounts of $\mathrm{ONOO}^{-}$in live cells and real water samples. This study offers insight into the development of displacement test based on fluorescent sensors with enhanced water solubility and biocompatibility.

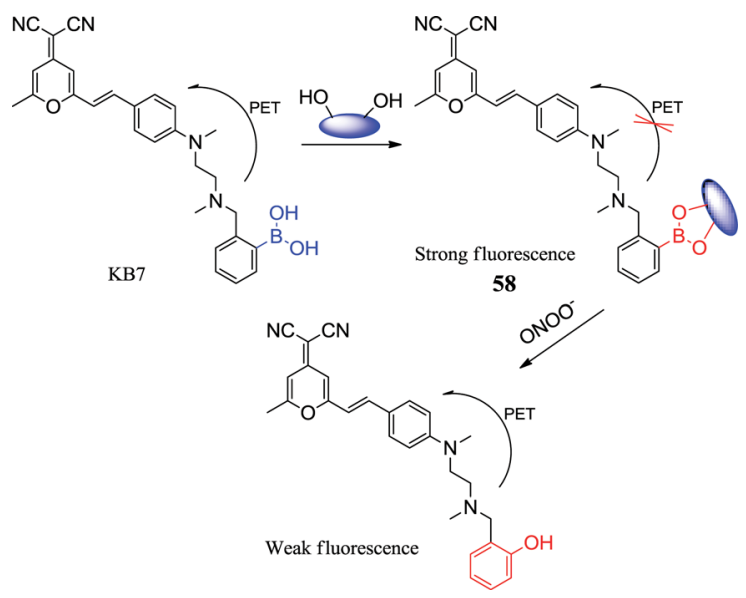

\section{Ions boronic acid sensors (Table 7)}

Owing to the simplicity and the low detection limit of the fluorescence, sensors based on the ion-induced changes in fluorescence have attracted numerous researchers devoting their time and energies to the investigation. Recently, an abundance of boronic acid sensors is fabricated to detect all kinds of ionic compounds, including fluoride sensors, ${ }^{17}$ copper ions, ${ }^{120,121}$ mercury ion, ${ }^{122}$ etc.

\subsection{Fluoride ion boronic acid sensors}

Low concentrations of fluoride anions have been shown to be effective in preventing dental caries, and their levels in water are above $4 \mathrm{ppm}$, which can seriously affect human health, such as fluorosis. It is becoming extremely important to monitor the concentration of fluoride in real time by the simple and efficient method. ${ }^{123}$ Mohammadpour et al. reported that carbon nanodots (CDs) can be used as a fluorescence platform for recognition of fluoride ions by the inner filter effect (IFE) of simple aryl boronic acid, and conducted the comprehensive experiments and theoretical studies of water-soluble fluoride sensors. ${ }^{17}$ The comparison of the UV spectra of NPBA and PBA has reflected that the acidic power of the NPBA's acid surpassed that of the PBA when adding the fluoride. It indicated a significant effect on the acidic power of the aromatic acid by the resonance overlap when the electron withdrawing groups was on the paraposition of the benzene ring. In this experimental condition, it was determined to achieve maximum fluorescence change when the NPBA concentration was adjusted to $0.5 \mathrm{mmol} \mathrm{L}^{-1}$ under buffer conditions (phosphate acetate $0.05 \mathrm{~mol} \mathrm{~L}^{-1}, \mathrm{pH} 4$ ) and after incubated for 5 minutes. The signal of the CDs/NPBA solution was gradually increasing and then suppressed when the concentration of fluoride ions was continuously increased. Furthermore, fluorescence signal changed with fluoride concentration manifesting a linear range of 0 to $15 \mathrm{mmol} \mathrm{L}^{-1}$, and the LOD value of $1.46 \times 10^{-4}$ (L) was still meeting EPA's safety requirements for water. Selective experiments indicated that the boron center of NPBA is highly selective for fluoride and has no significant affinity for chlorides, bromides, acetates, phosphates, and nitrates. Subsequently, DFT calculations indicated that the introduction of electron-withdrawing groups on the benzene ring of NPBA may increase the Lewis acids properties and facilitates to fabricate a more sensitive fluoride sensor.

Sensor 16 was reported by Huang et al. for recognizing Dglucose. Interestingly, it can detect fluoride ions in another sensing system. Wu et al. reported a sensing system based on sensor 16 capable of directly detecting fluoride ions. ${ }^{124}$ This is a combination of fluoride ions that triggers the aggregation of sensor 16 with catechol in an acidic aqueous solution, resulting in intense fluorescence changes. The fluoride binding constant is higher than $10^{3} \mathrm{~L} \mathrm{~mol}^{-1}$. This may be ascribed to the presence of the catechol increasing the Lewis acidity, thereby enhancing the fluoride affinity of the boronic acid. In addition, the boronate fluoride complex is mixed with bulk water to enhance the apparent fluoride affinity. 
Table 7 Key information of ionic compounds boronic acid sensors

\begin{tabular}{|c|c|c|c|c|}
\hline Sensor & Structure & $\begin{array}{l}\text { Spectroscopic } \\
\text { properties } \\
\left(\lambda_{\text {ex }} ; \lambda_{\text {em }}\right)\end{array}$ & $C$ (LOD; range) & Functions and applications \\
\hline $59^{120}$ & & $\begin{array}{l}450 \mathrm{~nm} ; \\
525 \mathrm{~nm}\end{array}$ & 一; 0-10 $\mu \mathrm{mol} \mathrm{L}^{-1}$ & $\begin{array}{l}\text { Red-shift, fluorescence intensity } \downarrow 75 \% \text {; } \\
\text { displaying high selectivity for } \mathrm{Cu}^{2+} \text { in } \\
\text { living cells, 59- } \mathrm{Cu}^{2+} \text { displayed fluorescence } \\
\text { enhancement with fructose, and the system } \\
\text { could be described as a } \\
\text { fluorescence INHIBIT logic gate }\end{array}$ \\
\hline $59 a^{120}$ & & $\begin{array}{l}450 \mathrm{~nm} ; \\
525 \mathrm{~nm}\end{array}$ & $-;-$ & $\begin{array}{l}\text { No fluorescence intensity changes; } \\
\text { suggesting the importance of the boronic } \\
\text { acid moiety in } 59 \\
\text { for the binding of } \mathrm{Cu}^{2+}\end{array}$ \\
\hline $59 b^{120}$ & & $\begin{array}{l}450 \mathrm{~nm} ; \\
525 \mathrm{~nm}\end{array}$ & -; - & $\begin{array}{l}\text { No fluorescence intensity changes; } \\
\text { suggesting the imine group plays a role } \\
\text { in the coordination of } \mathrm{Cu}^{2+}\end{array}$ \\
\hline $60^{121}$ & & $\begin{array}{l}270 \mathrm{~nm} ; \\
435 \mathrm{~nm}\end{array}$ & $-; 5 \times 10^{-3} \mathrm{~mol} \mathrm{~L}^{-1}$ & $\begin{array}{l}\text { Huge chemical shift, colourimetric } \\
\text { and "turn on" fluorescence sensor of } \mathrm{F}^{-} \text {; } \\
\text { distinct visual color changes } \\
\text { (colorless to yellow), a colorimetric } \\
\text { sensor for } \mathrm{Cu}^{2+} \text { in aqueous medium; } \\
\text { acting as colorimetric sensor for } \mathrm{Cu}^{2+} \text { and } \\
\text { colorimetric as well as } \\
\text { fluorimetric sensor for } \mathrm{F}^{-} \text {among } \\
\text { the studied ions }\end{array}$ \\
\hline $61^{122}$ & & $\begin{array}{l}510 \mathrm{~nm} ; \\
580 \mathrm{~nm}\end{array}$ & $\begin{array}{l}-; 3 \times 10^{-3} \\
\text { to } 1.5 \mathrm{~mol} \mathrm{~L}^{-1}\end{array}$ & $\begin{array}{l}\text { The colorimetric change, fluorescence } \\
\text { intensity } \uparrow \text {; "Off-On"-type fluorescent } \\
\text { and colorimetric changes for } \mathrm{Hg}^{2+}\end{array}$ \\
\hline $62^{122}$ & & $\begin{array}{l}510 \mathrm{~nm} \\
580 \mathrm{~nm}\end{array}$ & $\begin{array}{l}-; 3 \times 10^{-3} \\
\text { to } 0.6 \mathrm{~mol} \mathrm{~L}^{-1}\end{array}$ & $\begin{array}{l}\text { The colorimetric change, } \uparrow 9 \text {-fold; } \\
\text { "Off-On"-type fluorescent and colorimetric } \\
\text { changes for } \mathrm{Hg}^{2+}\end{array}$ \\
\hline $63^{126}$ & - & $\begin{array}{l}<400 \mathrm{~nm} ; \\
520,690 \mathrm{~nm}\end{array}$ & $\begin{array}{l}8 \mathrm{nmol} \mathrm{L}^{-1} ; \\
0.01 \text { to } 5 \mu \mathrm{mol} \mathrm{L}-1\end{array}$ & $\begin{array}{l}\text { Fluorescence intensity } \downarrow \text {, colorimetric sensor, } \\
\text { changed from blue to red; meeting the } \\
\text { requirement of the WHO standard for the } \\
\text { detection of the maximum allowable } \\
\text { level of } \mathrm{Hg}^{2+} \text { in drinking water }\end{array}$ \\
\hline $64^{129}$ & & $\begin{array}{l}319 \mathrm{~nm} ; \\
540 \mathrm{~nm}\end{array}$ & $645 \mathrm{ppm} ; 500 \mu \mathrm{mol} \mathrm{L}^{-1}$ & $\begin{array}{l}\text { Blue shift, color change from yellow to } \\
\text { colorless, fluorescence quenching; } \\
\text { selective fluorescent sensor toward } \mathrm{CN}^{-} \\
\text {in the presence of most competing anions }\end{array}$ \\
\hline $65^{132}$ & - & $\begin{array}{l}490 \mathrm{~nm} \\
540 \mathrm{~nm}\end{array}$ & $\begin{array}{l}0.28 \mu \mathrm{mol} \mathrm{L}{ }^{-1} \\
1.39 \text { to } 260 \mu \mathrm{mol} \mathrm{L}^{-1}\end{array}$ & Fluorescence intensity $\downarrow$; detecting $\operatorname{Cr}(\mathrm{vI})$ \\
\hline
\end{tabular}

\subsection{Copper ion boronic acid sensors}

Copper ions $\left(\mathrm{Cu}^{2+}\right)$ play a key role in the catalysis of cytochrome $\mathrm{C}$ oxidase, tyrosinase, etc. And excessive copper ions are highly toxic to organisms and can induce neurodegenerative diseases. ${ }^{125}$ Based on these biological implications, fluorescent sensors for $\mathrm{Cu}^{2+}$ have been extensively explored. Li et al. reported three fluorescent sensors (59, 59a and 59b). Wherein borate fluorescent sensor 59 showing high selectivity for $\mathrm{Cu}^{2+}$ in living cells, which uses naphthamide as a mother nucleus and boronic acid group as a binding site. ${ }^{120}$ This is few examples of boronic acid-based fluorescent chemosensors for $\mathrm{Cu}^{2+}$. The 
sensor 59 has a maximum absorbance at $450 \mathrm{~nm}$. With the increase of $\mathrm{Cu}^{2+}$ concentration $\left(0-300 \mathrm{~mol} \mathrm{~L}^{-1}\right)$, significant enhancement of absorption can be observed, and red shift to $465 \mathrm{~nm}$ occurs at the absorption maximum. Interestingly, the addition of $\mathrm{Cu}^{2+}$ significantly decreased the fluorescence intensity by $75 \%$ with a binding constant of $3.39 \times 10^{5} \mathrm{~mol} \mathrm{~L}^{-1}$, while the other ions did not cause significant fluorescence changes. In addition, fructose can increase the fluorescence of the chelates (sensor $59-\mathrm{Cu}^{2+}$ ) after $\mathrm{Cu}^{2+}$ induces a significant decrease in sensor 59 fluorescence intensity. Subsequently, they studied the ability of sensor 59 to detect $\mathrm{Cu}^{2+}$ in HeLa cells. Confocal microscopy showed that sensor $\mathbf{5 9}$ entered the cells and showed strong fluorescence in the absence of external copper ions. On the contrary, it was observed a very weak fluorescence response when 5 equivalents of $\mathrm{Cu}^{2+}\left(250 \mu \mathrm{mol} \mathrm{L}^{-1}\right)$ were added, illustrating quenching. These encouraging results have great guiding significance for the development of ion sensor systems.

Maity et al. reported on new boronic ester sensor $\mathbf{6 0}$ that can be used for the detection of both $\mathrm{Cu}^{2+}$ and $\mathrm{F}^{-}$ions. ${ }^{121}$ The addition of $\mathrm{F}^{-}$results in a change in the absorption spectral distribution, which may be ascribed to the coordination of $\mathrm{F}$ atoms on the electron-poor boron atoms, resulting in a small blue shift of the lowest energy absorption band, and excessive $\mathrm{F}^{-}$induce the deprotonation of the phenolic $\mathrm{O}-\mathrm{H}$ protons, resulting in a bright yellow color. The addition of $\mathrm{Cu}^{2+}$ may result in the charge transfer transition of phenoxide-O to $\mathrm{Cu}^{2+}$ in the resulting 2:1 complex to form a strong and beautiful yellow color. This sensor is capable of detecting both $\mathrm{Cu}^{2+}$ and $\mathrm{F}^{-}$ions as a very rare example.

\subsection{Mercury ion boronic acid sensors}

Inorganic mercury is one of the most common toxic metals in nature, and it may cause great damage to the brain, kidneys and endocrine systems. ${ }^{14}$ Therefore, the detection of mercury ions and mercury salts is of great significance. Kim et al. designed two new rhodamine fluorescent sensors with monoboronic acid and diboronic acid groups, respectively. The perchlorate salts of $\mathrm{Hg}^{2+}, \mathrm{Ag}^{+}, \mathrm{Ca}^{2+}, \mathrm{Cd}^{2+}, \mathrm{Co}^{2+}$, etc. were detected by both sensor $\mathbf{6 1}$ and sensor $62\left(3 \mu \mathrm{mol} \mathrm{L}{ }^{-1}\right)$ in $\mathrm{CH}_{3} \mathrm{CN} \cdot \mathrm{H}_{2} \mathrm{O}(9: 1)$ solution, respectively. The excitation and emission wavelengths were $510 \mathrm{~nm}$ and $580 \mathrm{~nm}$, respectively, and only the $\mathrm{Hg}^{2+}$ shows large fluorescence enhancement. ${ }^{\mathbf{1 2 2}}$ Fluorescence intensity increasing and colorimetric changes are ascribed to open lactam rings. $\mathrm{Hg}^{2+}$ complexation results in the conversion of caprolactam (non-fluorescent) to ring-opening amide (fluorescence), thus a switch type of fluorescent sensor was found. In this process, the boronic acid group and $\mathrm{Hg}^{2+}$ are combined into one unit. A library of rhodamine derivatives and other fluorophores can apply to a new switched-mode fluorescent sensor through similar transduction.

Zhou et al. have designed a simple and rapid colorimetric sensor $\mathbf{6 3}$ for detecting $\mathrm{Hg}^{2+}$ that induced AuNP aggregation by MPBA in an aqueous medium. ${ }^{126} \mathrm{Hg}^{2+}$ inhibited this aggregation, resulting in a visible color change of the AuNP solution from red to blue, while no significant color change was observed when other competing metal ions were added. It may be ascribed that the thiol group of MPBA preferentially binds to $\mathrm{Hg}^{2+}$ and MPBA loses the ability to induce AuNP aggregation. It has a good linear relationship in the concentration range from 0.01 to $5 \mu \mathrm{mol} \mathrm{L}{ }^{-1}$, and $R^{2}$ reaches 0.998 . The detection limit is 8 nmol L ${ }^{-1}$. Interestingly, Kong et al. developed a similar method and found $\mathrm{Hg}^{2+}$ inhibited AuNP aggregation, which can apply to detect $\mathrm{Hg}^{2+}$ in aqueous solutions. ${ }^{127}$

\subsection{Other ions boronic acid sensors}

The use of cyanide is widespread in chemical and related industries, which eventually accidental releases into the environment. Cyanide can inhibit cytochrome oxidase activity and is considered as one of the most toxic compounds. Normally, oral administration of a small amount of $\mathrm{CN}^{-}$solution is sufficient to cause death in a few minutes. Consequently, it is important to develop a highly sensitive sensor for $\mathrm{CN}^{-}$detection. ${ }^{16,128}$ Wang et al. fabricated boronic acid sensor 64 with 2aminophenol and (2-formylphenyl)boronic acid as raw materials. ${ }^{129}$ The sensor has a strong fluorescence efficiency at $540 \mathrm{~nm}$, which may be ascribed to the B-N interaction of the rigid five-membered ring framework. Interestingly, the fluorescence disappeared when added $\mathrm{CN}^{-}$. While the addition of $\mathrm{F}^{-}, \mathrm{Cl}^{-}, \mathrm{Br}^{-}, \mathrm{I}^{-}, \mathrm{NO}_{3}{ }^{-}, \mathrm{HSO}_{4}{ }^{-}, \mathrm{H}_{2} \mathrm{PO}_{4}{ }^{-}, \mathrm{AcO}^{-}$and $\mathrm{N}_{3}{ }^{-}$did not cause much fluorescence change. The detection limit of the boron-based receptor for $\mathrm{CN}^{-}$was determined to $645 \mathrm{ppm}$ by fluorescence titration experiments. In the past, most of the $\mathrm{CN}^{-}$ sensors relied on the interaction of hydrogen bonds to improve the selectivity. Furthermore, sensors were interfered by $\mathrm{F}^{-}$, $\mathrm{AcO}^{-}{ }^{-130}$ Boronic acid sensor 64 removes of those defects, and its own structure is simple and easy to fabricate.

Owing to mining, electroplating, dyes and other industries discharge a large amount of waste water containing $\mathrm{Cr}$, it brings great harm to the environment. The development of sensors capable of efficiently monitoring $\mathrm{Cr}$ in real time can undoubtedly control the random discharge of $\mathrm{Cr}$ and reduce the pollution of heavy metals to the environment. ${ }^{131}$ Tian et al. used 3aminophenylboronic acid as a starting material to prepare nitrogen and boron co-doped carbon dots sensor 65 that has a high quantum yield..$^{132}$ It has a good linear relationship in the concentration range from 1.39 to $260 \mu \mathrm{mol} \mathrm{L}^{-1}$, and $R^{2}$ reaches 0.997 . The detection limit is $0.28 \mu \mathrm{mol} \mathrm{L}^{-1}$. The synthesized N/ B-CD exhibited strong green fluorescence, which is applied to real sample detection. The moreover, the sensor was utilized for the analysis of dopamine in biological samples.

\section{Electrochemical boronic acid sensors}

Electrochemical sensors detect compounds by converting biological events to an electronic signal through the special combination or catalytic reaction on the electrode surface. ${ }^{133,134}$ The electrochemical biosensor is typically fabricated by modifying the surface of the metal and carbon electrode with special materials, such as polymers, self-assembled monolayers, organic oils, biomaterials (enzymes, antibodies), and so on. ${ }^{\mathbf{1 3 5}}$ 
One of the most widely studied electrochemical biosensors is based on ferrocene boronic acid (FcBA). ${ }^{136}$ Due to FcBA containing the unique properties of binding sites (boronic acid moieties) and electrochemically active moieties (Fc residues), ${ }^{\mathbf{1 3 7}}$ it is normally used for electrochemical sensing of ribose, ${ }^{\mathbf{1 3 8}}$ glycosylated hemoglobin (HbA1c) ${ }^{135}$ fluoride ion, ${ }^{139}$ etc. The basis of the electrochemical determination of carbohydrates mainly consists of two aspects. First, it is the cyclic borate formed by FcBA residues with 1,2- or 1,3-diols. Second, the redox properties of FcB-carbohydrates adducts are different from those of free FcBA. ${ }^{\mathbf{1 4 0}}$

It is generally accepted that microRNAs (miRNAs) play a key role in cancer diagnosis and prognosis serving as reliable molecular biomarkers. Xia et al. used FcBA as a redox marker and fabricated a label-free electrochemical sensor which is sensitive to miRNAs. ${ }^{138}$ The surface of the $\mathrm{Au}$ electrode was modified with a single molecular layer of single-stranded deoxyribonucleic acid (DNA). After incubation of the electrodes in the sample solution, FcBA was anchored to the ribose sugar in miRNAs via the formation of the boronic acid ester covalent bond. Consequently, miRNAs could be captured by the pre-immobilized DNA sensor and recognized by voltammetric measurement of FcBA. Due to the 1,2-diols function can't be used for DNA, FcBA can selectively recognize miRNAs in the concentration range of $5 \mathrm{nmol} \mathrm{L}^{-1}$ to $1 \mu \mathrm{mol} \mathrm{L}{ }^{-1}$.

Thakur et al. fabricated a new ferrocene-modified boronic acid sensor 66 and found the electrochemical and spectral properties in acetonitrile. ${ }^{139}$ The sensor exhibits large cathodic displacements of the redox potential of Fe (II/III) pairs when combined with fluoride ions $\left(K=10^{6} \mathrm{~L} \mathrm{~mol}^{-1}\right)$, whereas it displays a negligible affinity towards other effective competitors, such as $\mathrm{Cl}^{-}, \mathrm{Br}^{-}, \mathrm{I}^{-}, \mathrm{AcO}^{-}$. It indicated that the sensor has good selectivity for fluoride ion in organic solvents. Consequently, it can induce a strong color change from yellow to deep green associated with aerobic oxidation of the Fc moiety, and the fluorescence emission is quenched drastically. Due to the transformation of boronic esters to anionic borates, there is a strong effect on the redox potential and color adjacent to ferrocene. Therefore, it holds the potential to "naked eye" detection of fluoride ions.

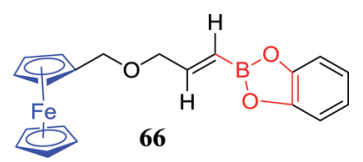

Zhou et al. developed a potentiometric method for the detection of sialic acid. ${ }^{\mathbf{1 4 1}}$ Glassy carbon (GC) electrodes were modified with poly(anilineboronic acid) (PABA) and electrodeposition of reduced graphene oxide (ERGO). The principle of sialic acid detection is ascribed to the reversible covalent bonds of PABA/ERGO/GC electrode. Boronic acid and diols formed a cyclic ester, as depicted in Fig. 10. Due to the introduction of the graphene layer on the electrode surface, the prepared electrochemical sensor significantly improved the sensitivity of the sensor response. Under the optimum conditions, the detection limit of the sensor is $0.8 \mu \mathrm{mol} \mathrm{L} \mathrm{L}^{-1}$ and the linear range is

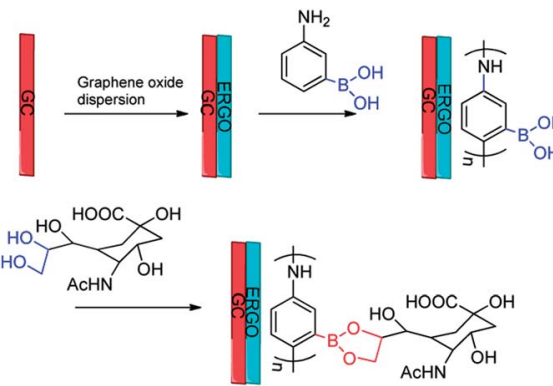

Fig. 10 Schematic illustration of modification progress of the GC electrode and the sensing mechanism of sialic acid. ${ }^{141}$

$2 \mu \mathrm{mol} \mathrm{L}{ }^{-1}$ to $1.38 \mathrm{mmol} \mathrm{L}^{-1}$. Furthermore, the electrochemical sensor has the advantages of good stability and high selectivity. It is able to accurately analyze sialic acid in human serum. The use of boronic acid electrochemistry as a new method of sensing carbohydrates and other substances holds the great potential in the practical applications.

\section{Smart polymeric materials boronic acid sensors (Table 8 )}

Incorporation of boronic acid groups into the polymer matrix can significantly enhance the binding. This boronic acid functional polymer dates back to the pioneering work of Wulff et al. ${ }^{\mathbf{1 4 2}}$ Smart polymers can convert the variation in external stimuli, such as temperature, $\mathrm{pH}$, or glucose level. Due to the stability, handling and biocompatibility of polymers, scientists tend to consider this smart polymer when fabricating sensors, including Asher et al. ${ }^{\mathbf{1 4 3}}$ Boronic acid functional polymers are extensively used, such as the modification of quantum dots (QDs) with PBA, ${ }^{\mathbf{1 1}, \mathbf{1 4 4}}$ the use of molecularly imprinted polymers, ${ }^{\mathbf{1 4 5}}$ the construction of multifunctional hybrid nanogels, ${ }^{\mathbf{1 0}}$ including the fluorescent beads mentioned above. ${ }^{61,62}$ Those molecular sensors that combined with smart polymers to detect D-glucose are receiving increasing attention.

\subsection{Quantum dot boronic acid sensors}

With the application of fluorescent sensors to protein labeling in living cells, it is more clearly understood dynamics of intracellular structures, signal transduction and interactions of cells, but more complex environmental requirements are encountered, such as the need for long observation times, masked signals from labeled molecules by cells autofluorescence, and so on. ${ }^{146}$ This requires new methods and tools. The size and shape of QDs can be precisely controlled by time, temperature, etc. Their energy levels are quantized with values directly related to the size (hence the name quantum dots). ${ }^{\mathbf{1 4 7}}$ Compared with traditional fluorophores, QDs with a diameter of several nanometers have broader band absorption spectrum and long fluorescence lifetime, which meet the needs of fluorescent sensors. ${ }^{148}$

Zhou et al. reported that the CdS QDs were immobilized in a microgel containing boronic acid groups and have a good 
Table 8 Key information of smart polymeric materials boronic acid sensors

\begin{tabular}{|c|c|c|c|c|}
\hline Sensor & Structure & $\begin{array}{l}\text { Spectroscopic } \\
\text { properties }\left(\lambda_{\text {ex }} ; \lambda_{\text {em }}\right)\end{array}$ & $C$ (LOD; range) & Functions and applications \\
\hline $67^{150}$ & - & $620 \mathrm{~nm} ; 736 \mathrm{~nm}$ & $0.2 \mu \mathrm{mol} \mathrm{L}^{-1} ; 0-400 \mu \mathrm{mol} \mathrm{L}^{-1}$ & $\begin{array}{l}\text { Fluorescence intensity } \downarrow \text {; applied to the detection of } \\
\text { dopamine in human serum sample }\end{array}$ \\
\hline $68^{151}$ & - & 一; $653 \mathrm{~nm}$ & $\begin{array}{l}23.1,118.7 \mu \mathrm{mol} \mathrm{L}^{-1} \\
0-30 \mathrm{mmol} \mathrm{L}^{-1}\end{array}$ & $\begin{array}{l}\text { Fluorescence intensity } \uparrow \text {; serving as "turn-on" detection of } \\
\text { glucose in blood serum }\end{array}$ \\
\hline $70^{160}$ & - & $360 \mathrm{~nm} ; 500 \mathrm{~nm}$ & $2 \mathrm{mg} \mathrm{mL}^{-1} ; 2$ to $75 \mathrm{mg} \mathrm{mL}^{-1}$ & $\begin{array}{l}\text { Fluorescence intensity } \uparrow \text {; easily synthesized and can be } \\
\text { stored for a period of long time for the detection based application }\end{array}$ \\
\hline $73^{170}$ & - & $302 \mathrm{~nm} ; 388 \mathrm{~nm}$ & -; 0-200 mmol L ${ }^{-1}$ & $\begin{array}{l}\text { Fluorescence intensity } \downarrow \text {, higher binding constant of sialic } \\
\text { acid compared to other carbohydrates } \\
\left(K_{\mathrm{pH} 7.4}=12.3, K_{\mathrm{pH} 6.5}=12.7\right) \text {; offering a highly translational approach } \\
\text { for clinical diagnosis and therapy of solid tumors }\end{array}$ \\
\hline
\end{tabular}

selectivity to glucose. ${ }^{144}$ For the expanded research, they modified CdTe/ZnTe/ZnS core-shell (CS) QDs with PBA, and incorporated them into mouse melanoma cells, as depicted in Fig. 11. As a result, they could successfully image mouse melanoma cells. ${ }^{11}$

Zhang et al. reported firstly the method of boron-doped graphene quantum dots (BGQD), which selectively recognize glucose on the surface of BGQD, ${ }^{149}$ as depicted in Fig. 12. This may be ascribed to the reaction of two cis-diols units in glucose with two boronic acid groups on the surface of BGQD. They produced a structurally rigid BGQD-glucose aggregation that limited intramolecular rotation, blocked nonradiative relaxation channels, and filled the radiation attenuation, resulting in a substantial increase in the strength of PL. Due to the absence of two cis-diols units, fructose, galactose or mannose were simply combined with BGODs containing exposed boronic acid groups, but couldn't be further combined to form an aggregation. They found that the signal intensity increases with increasing glucose concentration in the range of 0.1 to $10 \mathrm{mmol} \mathrm{L}^{-1}$, the detection limit is about $0.06 \mathrm{mmol} \mathrm{L}^{-1}$. This study brought a new scientific understanding of glucose detection.

Due to boronic acids formed stable boronate complexes with vicinal diols, Liu et al. functionalized water-soluble sensor $67\left(\mathrm{CuInS}_{2}\right.$ QDs) with 3-aminophenyl boronic acid by the one-step hydrothermal method. ${ }^{150}$ The $\mathrm{CuInS}_{2}$ QDs were covalently bound to the 3-aminophenyl boronic acid and formed 3-aminophenyl boronic acid functionalized $\mathrm{CuInS}_{2}$

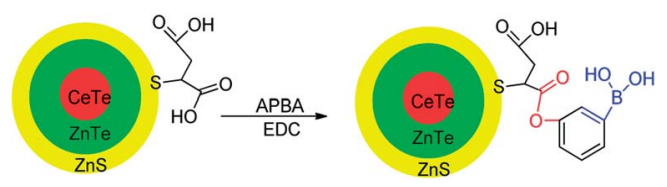

Fig. 11 Schematic illustration of modification progress of CdTe/ZnTe/ ZnS core-shell (CS) QDs with PBA. ${ }^{11}$ quantum dots (F-CuInS ${ }_{2}$-QDs). This sensor contained boronic acid groups, which were capable of reacting with ortho-diols to form a five- or six-membered cyclic ester in an aqueous alkaline solution. This combination caused $\mathrm{F}-\mathrm{CuInS}_{2}$-QDs fluorescence quenching. Consequently, the sensor could be applied to detect dopamine based on this property, as depicted in Fig. 13. Under the optimum conditions, the linear range of dopamine detection is 0.5 to $40 \mathrm{~mol} \mathrm{~L}^{-1}$, and the detection limit is $0.2 \mathrm{~mol} \mathrm{~L}^{-1}$.

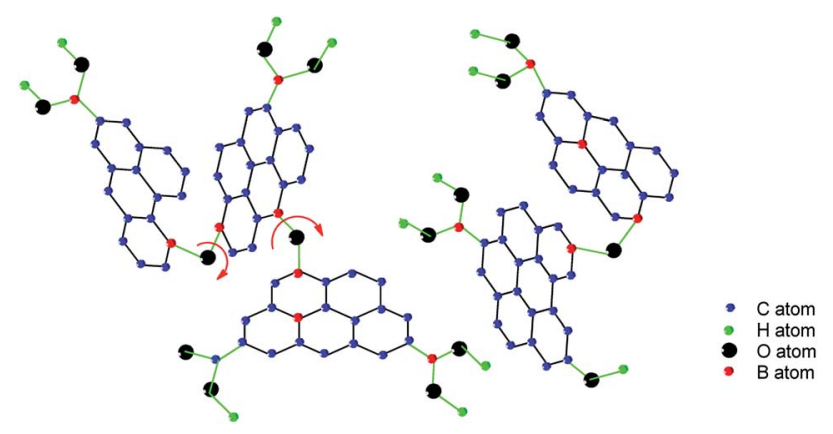

Fig. 12 Schematic illustration of the BGQD.149

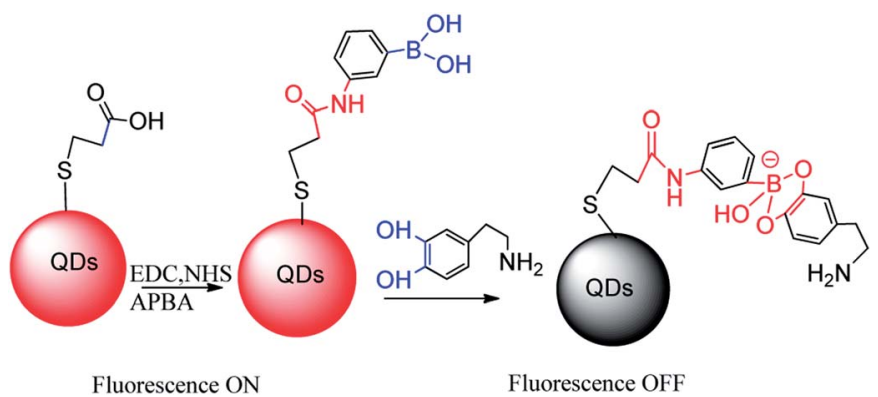

Fig. 13 Boronic acid QDs synthesis and dopamine detection diagram. ${ }^{150}$ 


\subsection{Smart polymer gels boronic acid sensors}

The microgels react with 1,2- or 5,6-cis-diols of glucose and form glucose bisboronate complexes, resulting in gel network shrinkage. Based on this nature, Zhou et al. prepared a highly selective glucose sensor 68, which had two boronic acid microgels (GS@(4-VPBA) and GS@pPBAs) with covalently immobilized graphene sheet (GS), ${ }^{151}$ as depicted in Fig. 14. The monolayer carbon atoms of graphene have a huge electron mobility, can induce the PBA ionization around graphene, making the microbial gel into a negatively charged at physiological pH 7.4. Glucose crosslinked with two boronic acid groups of microgels, causing microgel volume shrinkage and further leading to an increase in photoluminescence of graphene. However, the fructose and borate formed a monodentate complex, causing microgel volume expansion. The team had successfully applied this material to the detection of glucose in serum samples, which may open up new possibilities for the synthesis of potentially selective glucose-reactive microgels.

The hydrogel is a polymer network that can swell and retain aqueous solutions, meeting the need of functional and tunable biomaterials. ${ }^{152}$ Cai et al. synthesized a glucose-reactive hydrogel 69 that 3-acrylamidophenyl boronic acid copolymerized with ethylaminoethyl methacrylic (p(APBA-b-LAMA)). ${ }^{27}$ When glucose was added, the insulin release was significantly increased, indicating that glucose was triggered by the molecular exchange process. Subsequently, cytotoxicity analysis in vitro showed that the presence of carbohydrates polymers did not adversely affect cell proliferation. Due to the introduction of the carbohydrates moiety, cell compatibility of the carbohydrates-polymer hydrogel with PBA is significantly improved, which makes it potentially useful in the biomedical field. Consequently, the development of intelligent glucose response insulin delivery system in the treatment of diabetes has an important practical application.

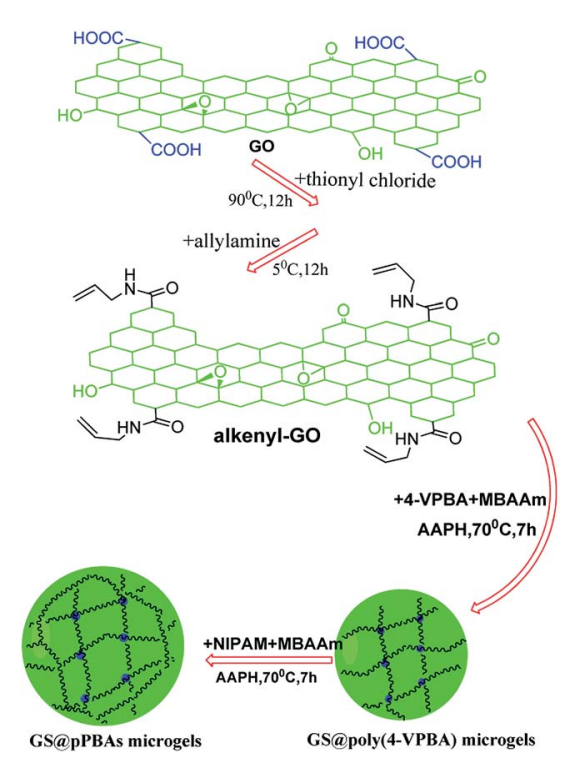

Fig. 14 Schematic illustration for the synthesis of GSapoly(4-VPBA) and GS@pPBAs microgels. ${ }^{151}$

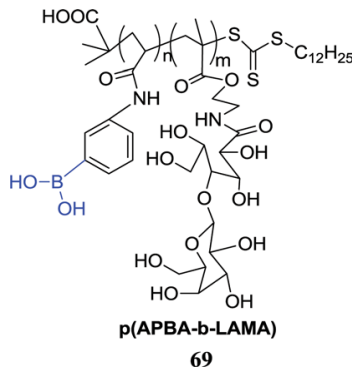

The molecularly imprinted polymer (MIP) is selectively detected the target compound by binding the binding cavity. Target compound polymerizes with the crosslinking agent and functional acceptor, and then binding cavity forms by removing the target compound under appropriate conditions, which is similar to target compound on size, shape and surface chemical properties. Owing to the prepared binding cavity is suitable for the target compound, selective recognition can be performed. ${ }^{153}$ Zhao et al. developed the biologically significant sensor for glucose, mannose, and galactose through the borate affinity MIP method, ${ }^{145}$ as depicted in Fig. 15. They converted glucose into diborate and then implanted it into the micelle by copolymerization with the methacrylate group in the micellar nucleus, followed by washing with different polar solutions to remove the glucose and obtained a binding cavity. The $K_{\mathrm{a}}$ value between MINP (glucose) and glucose is $1.18 \times 10^{3} \mathrm{~L} \mathrm{~mol}^{-1}$, and the $K_{\mathrm{a}}$ value of the other monosaccharides is negligible, which is in good agreement with the expected selective binding of the target compound. Molecular imprinting creates complementary objects that are increasingly popular, ${ }^{154}$ and the number of binding sites of per nanoparticle can be controlled by the ratio of surfactant to the target compound. It is completely watersoluble and can be used to precisely position and orient the binding groups on a cross-linked micelle, which distinguishes different carbohydrates.

\subsection{Nanosensors}

For small molecule sensors, there are some constraints to improving the selectivity by changing their structure, such as increasing the amount of boronic acid groups as recognition sites. Owing to the comfortable spatial position between boronic acids also plays an important role in the selectivity of the sensor, increasing the molecular structure undoubtedly increases the difficulty of synthesis. Thus, designing higher selective sensors requires the assistance of other fields of technology. Nanosensors have the high surface area, strong adsorption capacity and good electrical conductivity, which endows special properties to some small molecule sensors. Nanomaterials are very sensitive to changes in the external environment, such as temperature, light, humidity, etc., which can cause rapid changes in surface or interface ion valence and electron output. ${ }^{155}$ Therefore, the small molecule sensors connected to the nanomaterial interact with detection object causing a small change, which is amplified by the nanomaterial, making easily captured by the detector, thereby improving the selectivity and sensitivity of the sensor to a certain extent. Carbon nanometer is an ideal building material. For instance, 


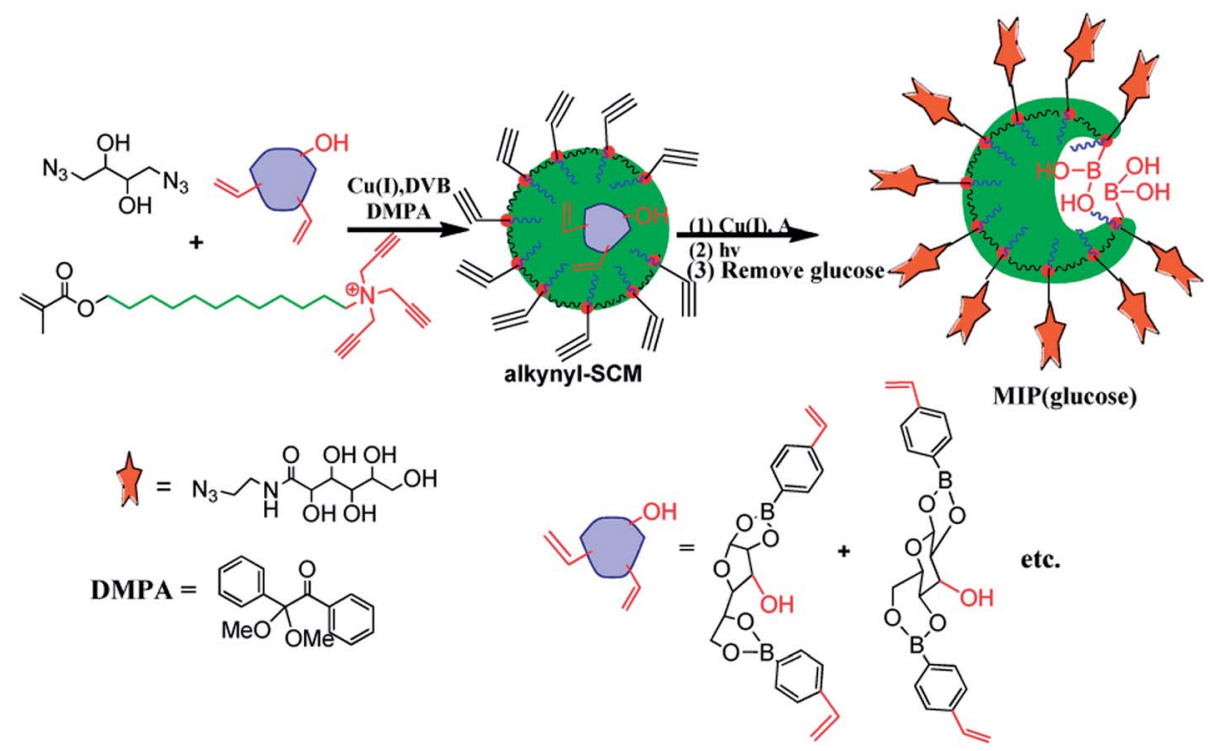

Fig. 15 Schematic illustration the progress of boronic acid-functionalized MINP for glucose. ${ }^{145}$

boronic acid modified carbon nanotubes (CNTs) can be prepared by a variety of sensors, one of which is near infrared reflection (NIR) optics glucose sensor for in vivo glucose monitoring prepared by combining boronic acid with single-walled CNTs (SWNT). ${ }^{\mathbf{1 5 6}}$ There are transistors composed of CNTs and pyrene boronic acid, which are used to detect D-glucose concentration. ${ }^{157}$ The content of D-glucose, D-fructose, and Dmannose in fruit juice can be determined by the glass carbon electrode modified with graphene oxide and 4-aminophenylboronic acid. ${ }^{158}$

7.3.1. Nanosensors for carbohydrates. Tatiana V. Shishkanova et al. had developed functional gold nanoparticles as sensing elements for electrochemical sensors to analyze neutral materials such as carbohydrates. ${ }^{159}$ They bound 4-mercaptophenylboronic acid to the surface of AuNPs through its thiol and introduced MPBA-AuNPs into the polymer matrix to prepare electrochemical sensors to detect neutral carbohydrates. Although carbohydrates are a neutral molecule, the interaction between PBA and carbohydrates leads to the release of protons, altering the proton concentration in the $\mathrm{pH}$ sensitive matrix of polyaniline (PANI) and resulting in generating an electric potential. The sensor has the following advantages. First, the sensor can analyze the neutral analyte. Second, it solves the compatibility issues between the ion carrier and the polymer matrix.

Basiruddin et al. reported on a fluorescent nanosensor 70 that can be applied to detect glucose. ${ }^{\mathbf{1 6 0}}$ It consists of phenylboronic acid functionalized reduced graphene oxide (rGO PBA) and diol-modified fluorescent sensor. Diol modified fluorescent sensor and rGO PBA form cyclic ester bonds, leading to fluorescence quenching. However, after addition of glucose, glucose replaces the diol-modified fluorescent sensor on the GO and forms a new cyclic boronate $\mathbf{7 1}$ with rGO PBA, thereby starting fluorescence. Glucose concentrations in the range of $2 \mathrm{mg} \mathrm{mL}^{-1}$ to $75 \mathrm{mg} \mathrm{mL}^{-1}$ can be tracked by this fluorescent nanosensor.
Due to their ease of synthesis and long-term storage, nanosensors can be designed as drug delivery drug carriers for the detection of various cancer cells.

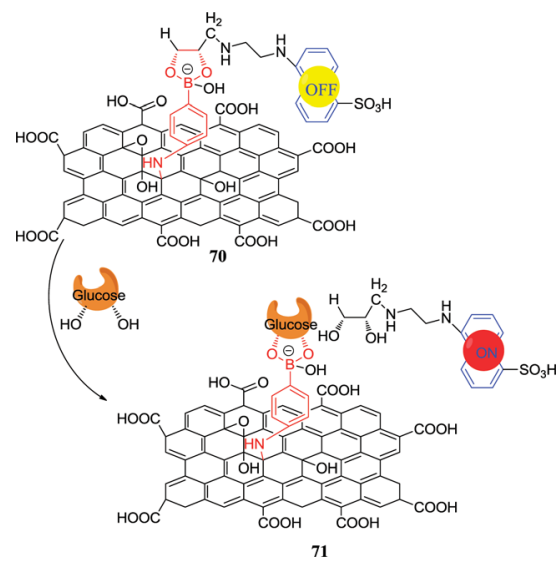

Ouyang et al. reported an ultra-sensitive solid phase microextraction (SPME) sensor 72. It was fabricated by PBA functionalizing CNTs and successfully applied to direct recognition of carbohydrates in biological fluids and semi-solid biological tissue in vitro or in vivo. ${ }^{\mathbf{1 6 1}}$ First, PBA functionalized CNTs acted as carbohydrates nanoreceptors. Nano-receptors hybridized with acid resisting polyacrylonitrile (PAN) groups in an appropriate ratio and then linked to a pretreated quartz fiber via the dip-coating method. In this progress, 3D interconnected architecture was formed, which facilitated the sensor binding to carbohydrates, and its enrichment factor was up to 151 . The proposed sensor is able to couple with GC-MS after changing the $\mathrm{pH}$, which is remarkably increasing the sensitivity of carbohydrates recognition, as depicted in Fig. 16. The sensor offered a specific scaffold of the diols unit, in particular, cisdiols. Thus carbohydrates that have various 1,3 or 1,2 cis-diols units can be easily captured by the scaffolds. Up until now, the 

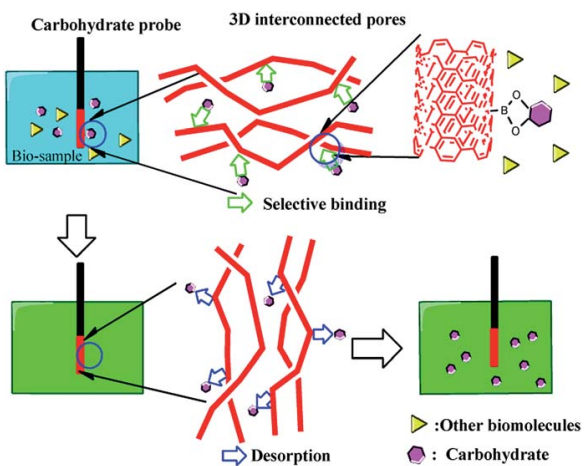

Fig. 16 Schematic illustration of saccharides sensing by means of the PBA-functionalized CNTs. ${ }^{161}$

sensor was far superior to other sensors that were widely used for bioanalysis, including polydimethylsiloxane (PDMS) ${ }^{\mathbf{1 6 2 , 1 6 3}}$ and $\mathrm{C} 18,{ }^{164}$ and they were ideally suited for the identification and differentiation of carbohydrates in multi-carbohydrates systems. Compared to most carbohydrates sensors, the sensor has higher sensitivity, wider linear range and excellent qualitative ability in multi-carbohydrates systems. Consequently, this approach holds the unique potential of new avenues for the facile and efficient recognition of carbohydrates.

Based on the principle that boronic acid forms a reversible five- or six-membered cyclic boronic esters with cis-1,2- or 1,3diols, Ramsay et al. reported the identification and discrimination of mixtures containing different components of carbohydrates by single molecule analysis. ${ }^{165}$ According to the fluctuation of the ion current generated by the binding of the boronic acid-modified engineering protein nanopore to different sugars, this method can determine the binding mode, thereby realizing the differentiation of different carbohydrates. In the disaccharide (D-maltose) and monosaccharide (D-glucose) mixture components, it is easy to discriminate by visually checking the current recording. In the monosaccharide mixed components, the characteristics of D-glucose and D-fructose can be distinguished by dwell-time analysis. Owing to distinguishing multi-component carbohydrates, this single-molecule analysis method is beneficial to improve the accuracy of blood glucose monitoring and will have a great impact on the design of continuous blood glucose monitoring devices for medical diagnosis. Similarly, Nishino et al. reported a supramolecular strategy for carbohydrates detection by single molecule junction. ${ }^{\mathbf{1 6 6}}$ Owing to only glucose forms a single molecule junction composed of 1:2 monosaccharide 4MPBA supramolecular complex, this strategy can contribute toward the achievement of minimally invasive glucose sensing.

7.3.2. Nanosensors for glycoproteins. Zhang et al. firstly reported a novel fluorescent nanosensor for selective monitoring of glycoproteins. ${ }^{167}$ This nanosensor, which regulated the recognition of glycoproteins by controlling $\mathrm{pH}$ and temperature, was based on molecularly imprinted spatial structures and borate affinity. The team obtained the glycoprotein template by copolymerizing OVDAC-coated CdTe nanocrystals (NCs) with NIPAAm of the temperature-sensitive element and VPBA of the recognition element, and successfully applied to detection of horseradish peroxidase (HRP) in human urine samples, as depicted in Fig. 17. This study provides a simple and effective fluorescent tool for the diagnosis of clinical glycoproteins.

7.3.3. Nanosensors for sialic acid. Targeting recognition of tumors by nanoparticles is an effective method of improving the efficiency of chemotherapy. ${ }^{\mathbf{1 6 8}}$ The expression of sialoglycans in tumor cells provides a favorable target. ${ }^{77}$ Owing to PBA can selectively recognize sialic acid, ${ }^{169}$ Deshayes et al. had developed PBA-conjugated micellar nanoparticles $\mathbf{7 3}$ combining the maternal complex of anticancer drug oxaliplatin. The micellar nanoparticles can target cancer cells containing overexpression of sialic acid epitopes. ${ }^{170}$ After assembly of the PBA, the micelles show high affinity for sialic acid and are confirmed by fluorescence spectroscopy in tumor cells. At pH 6.5, micelles could improve the capacity of recognition and uptake of tumor cells, thereby enhancing the cytotoxicity of drugs on B16F10 murine melanoma cells in vitro. The incorporation of PBA complex micelles could effectively reduce the growth rate of melanoma in situ and lung metastatic models. Those studies indicated that nanoparticles in combination with PBA can achieve tumortargeted therapy and provide a method for clinical diagnosis and therapy of solid tumors, as depicted in Fig. 18.

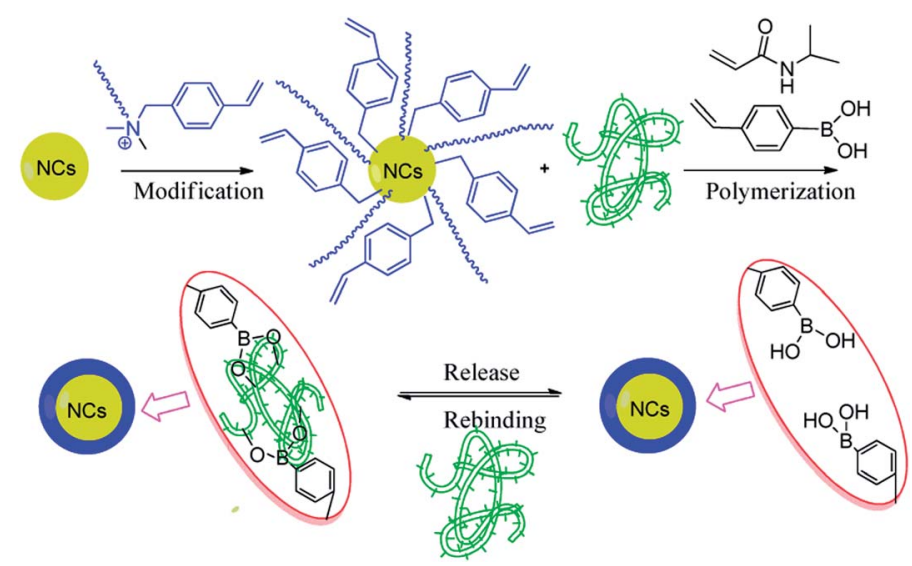

Fig. 17 Schematic illustration of NCs self-assembly and sensing progress. ${ }^{167}$ 


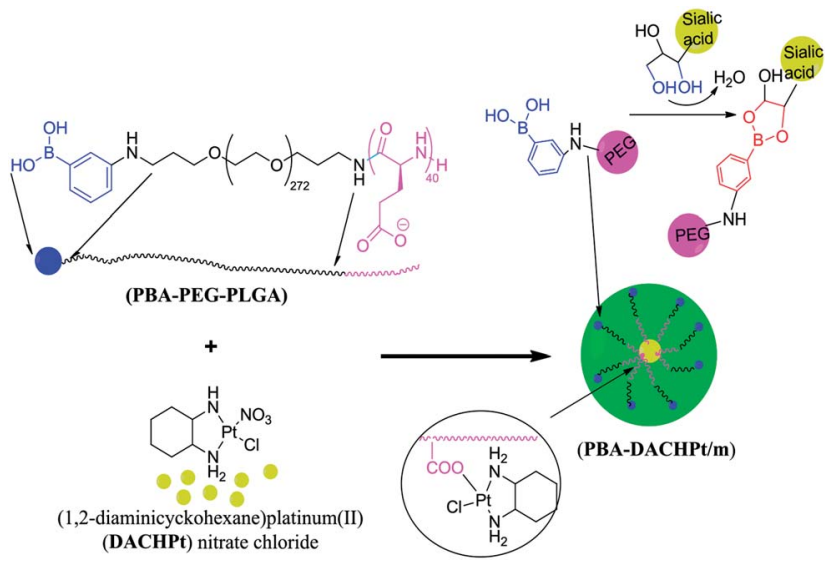

Fig. 18 PBA moieties on the surface of the nanocarriers can identify sialic acid. ${ }^{170}$

7.3.4. Nanosensors for DNA. Chen et al. developed a spectroscopic method based on the boronic acid functional nanospheres fluorescent sensor $\mathbf{7 4}$ to determine the 5hydroxymethylcytosine $(5 \mathrm{hmC})$ content of genomic DNA in tissue samples, ${ }^{171}$ as depicted in Fig. 19. Firstly, PBAQA-PGMA nano-microsphere were prepared by emulsion polymerization. And then T4- $\beta$-glucosyl-transferase ( $\beta$-GT) transferred glucose from uridine diphosphate glucose (UDP-Glu) to $5 \mathrm{hmC}$ and glucosylated 5 hmC DNA (G-5 hmC-DNA) was obtained. ${ }^{172}$

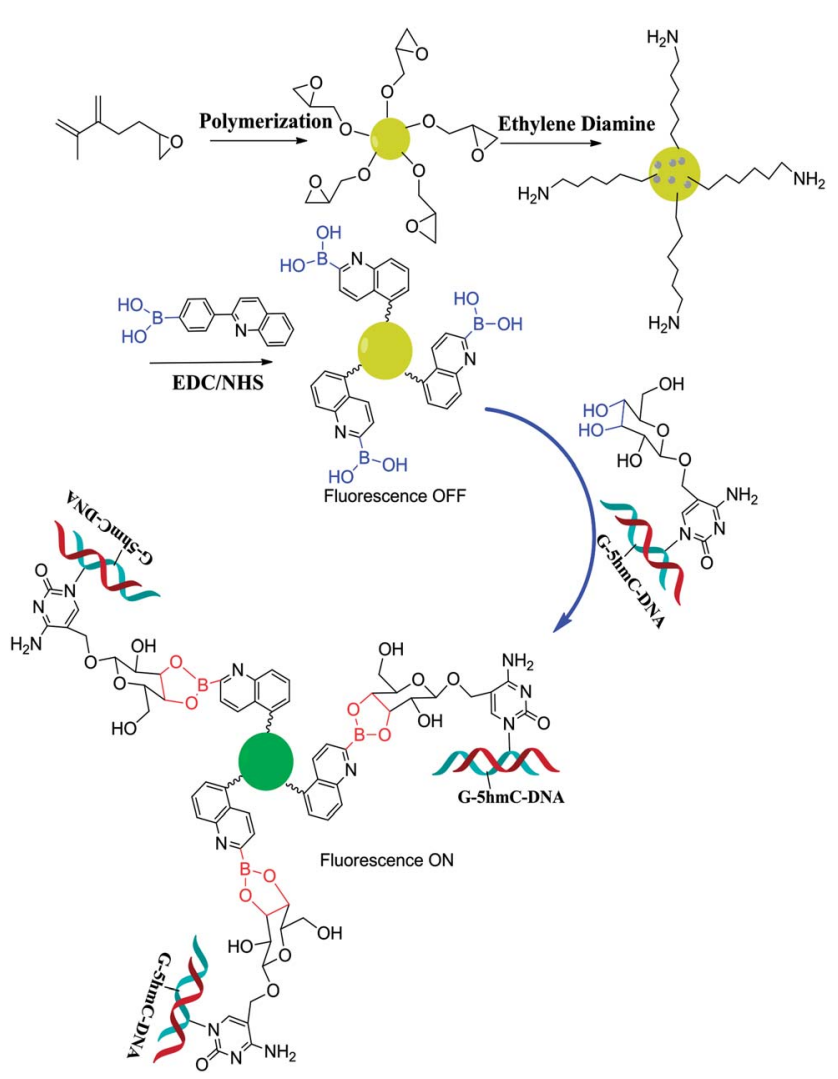

Fig. 19 Schematic illustration of the quantification of $5 \mathrm{hmC}$ content in genomic DNA using the PBAQA-PGMA sensor. ${ }^{171}$
Finally, the boronic acid groups of the PBAQA-PGMA sensor interacted with the glucose moiety of the G-5hmC-DNA and formed a boronic acid ester, enhancing the fluorescence signal. The fluorescence signal of the DNA sample solution was proportional to the content of $5 \mathrm{hmC}$. Furthermore, the PBAQAPGMA sensor could gather G-5hmC-DNA from complex raw materials containing a low content of $5 \mathrm{hmC}$, which facilitated to increase its sensitivity. They found that the fluorescence intensity increased with increasing $5 \mathrm{hmC}$ concentration in the range of 0 to $100 \mathrm{nmol} \mathrm{L}^{-1}$, the detection limit was about 0.167 $\mathrm{nmol} \mathrm{L}{ }^{-1}$. The sensor displays good detection sensitivity and selectivity and holds great potential to be an effective diagnostic and prognostic tool for the disease in the term of the physiological significance of $5 \mathrm{hmC}$.

\section{Conclusions and perspective}

Boronic acids have been successively developed as fluorescent sensors for carbohydrates since the phenomenon that boronic acids and 1,2-dihydroxy or 1,3-dihydroxy group can reversibly bind in an aqueous solution was reported in 1959. These sensors are based on different fluorescence mechanisms such as PET, FRET and so on, which can combine with carbohydrates to achieve off-on or on-off fluorescence changes. Owing to the carbohydrates have multiple binding sites, the diboronic acid having a specific structure can significantly increase the affinity and selectivity for certain carbohydrates. The selective recognition of carbohydrates, especially those with physiological and pathological functions, is of great significance for the in-depth study of related diseases. For example, glucose selective fluorescent sensors provide great help for the diagnosis and treatment of diabetes. Fluorescent sensors targeting tumor cell surface-specific sialyl Lewis oligosaccharide lay a foundation for tumor cell imaging and in vivo imaging. Early effective diagnosis and screening of cancer have always been the direction of scientists' constant efforts. In this regard, boronic acid fluorescent sensors may provide an effective strategy. In addition, there are many reports on the identification of boronic acid sensors such as catecholamines, various ions, and reactive oxygen species. They are expected to be utilized in several analytical tasks in the future, including on-site diagnosis of disease,${ }^{173}$ detections of ionic compounds, ${ }^{14-17}$ protein modifications, ${ }^{174}$ or cancer cells imaging. ${ }^{24,77}$

In recent years, the design of boronic acid sensors has become more sophisticated, and the more fields involved. As mentioned in the review above, the selectivity can be increased by adding a boronic acid groups to the molecular structure and maintaining a comfortable spatial position, or by connecting a new material such as a quantum dots to increase the fluorescence intensity. Some new material fields endow unique properties to boronic acid sensors. For example, a smart gel that forms a multifunctional hybrid nanogel with boronic acids can respond to the release of insulin regulation by a glucose sensor detecting the blood glucose concentration. Owing to smart gels can remain in patients for long periods of time, hydrogels with highly selective glucose sensors have enormous potential for clinical treatment of diabetes. ${ }^{175}$ Simultaneously, some research 
has focused on exploiting next-generation functional materials for other uncharted regions, such as PBA-modified QDs, ${ }^{150}$ PBA functionalized CNTs, ${ }^{156}$ boronic acid functionalized gold nanoparticles as electrochemical sensing elements, ${ }^{159}$ etc.

Although there are many fluorescent sensors reported so far, most of the discovery strategies are based on blind screening, and the hit rate is not high. A truly effective borate screening model for a target carbohydrates, especially related models based on computer-aided design, is rarely reported. The main reason is the compatibility of boronic acids in some calculation software, and some parameters combined in aqueous solution are difficult to simulate with calculation software. With the increasing number of boronic acid sensors reported so far, if we can summarize the relevant binding rules and structure-activity relationships, and establish an effective screening model to achieve a "rational design" of boronic acid sensors, it will greatly save development time and cost. Sensors targeting tumor cell surface-specific oligosaccharides have been reported now. However, due to the complexity of the physiological environment in the body and many interference factors, there is still a long way to go before they can be applied to human body. In the future, if breakthroughs can be made in terms of selectivity and fluorescence properties, achieving early diagnosis of diseases, tumor treatment and prognosis will be the gospel of cancer patients and all human beings. From a personal perspective, the research of boronic acid sensors is as hot now as it has ever been. We anticipate that this review will inspire others to explore more practical boronic acid sensors.

\section{Conflicts of interest}

The authors confirm that this article content has no conflict of interest.

\section{Acknowledgements}

The authors would like to thank the Innovation Project of Shandong Academy of Medical Sciences for financial support. This work was supported by Shandong Provincial Natural Science Foundation, China (Grant No. ZR2014YL035), Shandong Academy of Medical Sciences Foundation (Grant No. 20165), Shandong Provincial Natural Science Foundation, China (Grant No. ZR2017PH003).

\section{Notes and references}

1 X. Sun and T. D. James, Chem. Rev., 2015, 115, 8001-8037.

2 B. Breiten, M. R. Lockett, W. Sherman, S. Fujita, M. Alsayah, H. Lange, C. M. Bowers, A. Heroux, G. Krilov and G. M. Whitesides, J. Am. Chem. Soc., 2013, 135, 1557915584.

3 M. R. Lockett, H. Lange, B. Breiten, A. Heroux, W. Sherman, D. Rappoport, P. O. Yau, P. W. Snyder and G. M. Whitesides, Angew. Chem., Int. Ed., 2013, 52, 7714-7717.

4 X. Wu, X. X. Chen and Y. B. Jiang, Analyst, 2017, 142, 14031414.
5 Y. Kubo, R. Nishiyabu and T. D. James, Chem. Commun., 2015, 51, 2005-2020.

6 N. Siddiqui, N. Billa, C. Roberts and Y. A. Osei, Pharmaceutics, 2016, 8, 30.

7 J. Jagur-Grodzinski, Polym. Adv. Technol., 2010, 21, 27-47.

8 Y. Guan and Y. Zhang, Chem. Soc. Rev., 2013, 42, 8106-8121.

9 G. Kaur, H. Fang, X. Gao, H. Li and B. Wang, Tetrahedron, 2006, 62, 2583-2589.

10 W. Wu, N. Mitra, E. C. Y. Yan and S. Zhou, ACS Nano, 2010, 4, 4831-4839.

11 W. Wu, T. Zhou, A. Berliner, P. Banerjee and S. Zhou, Angew. Chem., Int. Ed., 2010, 49, 6554-6558.

12 Y. J. Huang, W. J. Ouyang, X. Wu, Z. Li, J. S. Fossey, T. D. James and Y. B. Jiang, J. Am. Chem. Soc., 2013, 135, 1700-1703.

13 W. Zhai, L. Male and J. S. Fossey, Chem. Commun., 2017, 53, 2218-2221.

14 X. Zhu, X. Zhou and D. Xing, Biosens. Bioelectron., 2011, 26, 2666-2669.

15 R. Guan, H. Chen, F. Cao, D. Cao and Y. Deng, Inorg. Chem. Commun., 2013, 38, 112-114.

16 S. A. Lee, G. R. You, Y. W. Choi, H. Y. Jo, A. R. Kim, I. Noh, S. J. Kim, Y. Kim and C. Kim, Dalton Trans., 2014, 43, 66506659.

17 Z. Mohammadpour, A. Safavi, A. Omidvar, A. Mohajeri, N. Mobaraki and M. Shamsipur, J. Fluorine Chem., 2016, 190, 12-22.

18 Y. Ooyama, A. Matsugasako, K. Oka, T. Nagano, M. Sumomogi, K. Komaguchi, I. Imae and Y. Harima, Chem. Commun., 2011, 47, 4448-4450.

19 Y. Ooyama, K. Furue, K. Uenaka and J. Ohshita, RSC Adv., 2014, 4, 25330-25333.

20 C. Chung, D. Srikun, C. S. Lim, C. J. Chang and B. R. Cho, Chem. Commun., 2011, 47, 9618-9620.

21 H. Nonaka, Q. An, F. Sugihara, T. Doura, A. Tsuchiya, Y. Yoshioka and S. Sando, Anal. Sci., 2015, 31, 331-335.

22 Ý. L. Du, N. Ni, M. Li and B. Wang, Tetrahedron Lett., 2010, 51, 1152-1154.

23 A. Chaicham, S. Sahasithiwat, T. Tuntulani and B. Tomapatanaget, Chem. Commun., 2013, 49, 9287-9289.

24 M. H. Chang and C. N. Chang, Tetrahedron Lett., 2014, 55, 4437-4441.

25 Y. Chu, D. Wang, K. Wang, Z. L. Liu, B. Weston and B. Wang, Bioorg. Med. Chem. Lett., 2013, 23, 6307-6309.

26 H. Fu, H. Fang, J. Sun, H. Wang, A. Liu, J. Sun and Z. Wu, Curr. Med. Chem., 2014, 21, 3271-3280.

27 B. Cai, Y. Luo, Q. Guo, X. Zhang and Z. Wu, Carbohydr. Res., 2017, 445, 32-39.

28 S. Huang, M. Jia, Y. Xie, J. Wang, W. Xu and H. Fang, Curr. Med. Chem., 2012, 19, 2621-2637.

29 R. Danne, C. Poojari, H. Martinez-Seara, S. Rissanen, F. Lolicato, T. Róg and I. Vattulainen, J. Chem. Inf. Model., 2017, 57, 2401-2406.

30 Y. Li, S. Li and L. Huang, Oncol. Res., 2018, 26, 123-130.

31 K. A. Green, Y. Becker, A. Tanaka, D. Takemoto, H. L. Fitzsimons, S. Seiler, H. Lalucque, P. Silar and B. Scott, Mol. Microbiol., 2017, 103, 657-677. 
32 A. Aroca, J. M. Benito, C. Gotor and L. C. Romero, J. Exp. Bot., 2017, 68, 4915-4927.

33 R. Emmerstorfer, K. Radefeld, V. Havlicek, U. Besenfelder, H. Yu, C. Mayrhofer, C. Vogl, G. Brem and S. Papp, Reprod., Fertil. Dev., 2017, 30, 205-206.

34 N. K. Broeker, D. Andres, Y. Kang, U. Gohlke, A. Schmidt, S. Kunstmann, M. Santer and S. Barbirz, Perspect. Sci., 2017, 11, 45-52.

35 J. P. Lorand and J. O. Edwards, J. Org. Chem., 1959, 24, 769774.

36 G. Springsteen and B. Wang, Chem. Commun., 2001, 16081609.

37 G. Springsteen and B. Wang, Tetrahedron, 2002, 58, 52915300.

38 T. D. James, K. R. A. S. Sandanayake and S. Shinkai, Angew. Chem., Int. Ed. Engl., 1994, 33, 2207-2209.

39 X. Wu, Z. Li, X. X. Chen, J. S. Fossey, T. D. James and Y. B. Jiang, Chem. Soc. Rev., 2013, 42, 8032-8048.

40 S. Jiang, J. O. Escobedo, K. K. Kim, O. Alptürk, G. K. Samoei, S. O. Fakayode, I. M. Warner, O. Rusin and R. M. Strongin, J. Am. Chem. Soc., 2006, 128, 12221-12228.

41 X. Zhang, B. Chen, M. He, Y. Zhang, L. Peng and B. Hu, Analyst, 2016, 141, 1286-1293.

42 T. M. Tran, Y. Alan and T. E. Glass, Chem. Commun., 2015, 51, 7915-7918.

43 J. S. Hansen, T. Hoeg-Jensen and J. B. Christensen, Tetrahedron, 2017, 73, 3010-3013.

44 L. Wang, L. Yuan, X. Zeng, J. Peng, Y. Ni, J. C. Er, W. Xu, B. K. Agrawalla, D. Su and B. Kim, Angew. Chem., 2016, 55, 1773-1776.

45 G. Jiang, W. Zhu, X. Shen, L. Xu, X. Li, R. Wang, C. Liu and X. Zhou, Microchim. Acta, 2017, 1-8.

46 S. J. Jung, J. Y. Lee, T. H. Kim, D. E. Lee, J. Jeon, S. D. Yang, G. H. Min, J. J. Min and D. P. Yong, Bioorg. Med. Chem. Lett., 2016, 26, 1784-1788.

47 J. Yoon and A. W. Czarnik, J. Am. Chem. Soc., 1992, 114, 276277.

48 F. P. Schwarz and S. P. Wasik, Anal. Chem., 1976, 48, 524528.

49 J. Yoon and A. W. Czarnik, Bioorg. Med. Chem., 1993, 1, 267271.

50 T. D. James, K. R. A. S. Sandanayake and S. Shinkai, J. Chem. Soc., Chem. Commun., 1994, 47, 477-478.

51 T. D. James, R. Iguchi and S. Shinkai, J. Am. Chem. Soc., 1995, 117, 8982-8987.

52 M. A. Fox, Photochem. Photobiol., 1990, 52, 617-627.

53 J.-r. Wei, Y.-l. Ni, W. Zhang, Z.-q. Zhang and J. Zhang, Anal. Chim. Acta, 2017, 960, 110-116.

54 S. Cecioni and D. J. Vocadlo, J. Am. Chem. Soc., 2017, 139, 8392-8395.

55 X. Sun, T. D. James and E. V. Anslyn, J. Am. Chem. Soc., 2018, 140, 2348-2354.

56 H. Eggert, J. Frederiksen, C. Morin and J. C. Norrild, ChemInform, 1999, 64, 3846-3852.

57 Y. Liu, C. Deng, L. Tang, A. Qin, R. Hu, J. Z. Sun and B. Z. Tang, J. Am. Chem. Soc., 2011, 133, 660-663.
58 M. Shao and Y. Zhao, Tetrahedron Lett., 2010, 51, 25082511.

59 C. Wang, Y. Li and Y. Wei, Sens. Actuators, B, 2017, 247, 595601.

60 T. Kawanishi, M. A. Romey, P. C. Zhu, M. Z. Holody and S. Shinkai, J. Fluoresc., 2004, 14, 499-512.

61 H. Shibata, Y. J. Heo, T. Okitsu, Y. Matsunaga, T. Kawanishi and S. Takeuchi, Proc. Natl. Acad. Sci. U. S. A., 2010, 107, 17894-17898.

62 Y. J. Heo, H. Shibata, T. Okitsu, T. Kawanishi and S. Takeuchi, Proc. Natl. Acad. Sci. U. S. A., 2011, 108, 13399-13403.

63 S. Arimori, M. L. Bell, C. S. Oh and T. D. James, Org. Lett., 2002, 4, 4249-4251.

64 R. M. Clegg, Curr. Opin. Biotechnol., 1995, 6, 103-110.

65 Y. J. Huang, Y. B. Jiang, S. D. Bull, J. S. Fossey and T. D. James, Chem. Commun., 2016, 52, 3456-3469.

66 S. Jin, Y. Cheng, S. Reid, M. Li and B. Wang, Med. Res. Rev., 2010, 30, 171-257.

67 Z. Sharrett, S. Gamsey, L. Hirayama, B. Vilozny, J. T. Suri, R. A. Wessling and B. Singaram, Org. Biomol. Chem., 2009, 7, 1461-1470.

68 R. Badugu and C. D. Lakowicz JRGeddes, Bioorg. Med. Chem., 2005, 13, 113-119.

69 D. Bruen, C. Delaney, L. Florea and D. Diamond, Sensors, 2017, 17, 1866.

70 B. Liu, N. Novikova, M. C. Simpson, M. S. Timmer, B. L. Stocker, T. Söhnel, D. C. Ware and P. J. Brothers, Org. Biomol. Chem., 2016, 14, 5205-5209.

71 J. Axthelm, A. Shc, M. Elstner, U. R. Gandra, H. Görls, P. Bellstedt and A. Schiller, J. Am. Chem. Soc., 2017, 139, 6165-6170.

72 H. Li, L. Zhu, X. Zhu and H. Zhang, Sens. Actuators, B, 2017, 246, 819-825.

73 N. Dey and S. Bhattacharya, Chem.-Eur. J., 2017, 23, 1654716554.

74 X. T. Zhang, S. Wang and G. W. Xing, Chem.-Asian J., 2015, 10, 2594-2598.

75 L. C. Samaniego, M. A. Lago Huvelle, M. L. Uhrig, L. F. Coluccio and C. C. Spagnuolo, Chem. Commun., 2015, 51, 4895-4898.

76 X. D. Xu, H. Cheng, W. H. Chen, S. X. Cheng, R. X. Zhuo and X. Z. Zhang, Sci. Rep., 2013, 3, 2679.

77 T. M. Kolben, F. Kraft, T. Kolben, C. Goess, A. Semmlinger, C. Dannecker, E. Schmoeckel, D. Mayr, N. N. Sommer, S. Mahner and U. Jeschke, Future Oncol., 2017, 13, 145-157.

78 W. Yang, S. Gao, X. Gao, V. V. Karnati, W. Ni, B. Wang, W. B. Hooks, J. Carson and B. Weston, ChemInform, 2002, 12, 2175-2177.

79 Y. E. Wang, R. X. Rong, H. Chen, M. Y. Zhu, B. H. Wang and X. L. Li, Chin. Chem. Lett., 2017, 28, 1262-1267.

80 Y. Wang, R. Rong, H. Chen, M. Zhu, B. Wang and X. Li, Bioorg. Med. Chem. Lett., 2017, 27, 1983-1988.

81 D. Wang, E. Ozhegov, L. Wang, A. Zhou, H. Nie, Y. Li and X. L. Sun, Glycoconjugate J., 2016, 33, 725-733.

82 A. Varki and P. Gagneux, Ann. N. Y. Acad. Sci., 2012, 1253, 16-36. 
83 H. Wang, M. He, B. Chen and B. Hu, J. Anal. At. Spectrom., 2017, 32, 1650-1659.

84 J. Runhaar, R. Rozendaal, M. v. Middelkoop, J. Bijlsma, M. Doherty, K. Dziedzic, L. Lohmander, T. McAlindon, W. Zhang and S. Bierma-Zeinstra, Ann. Rheum. Dis., 2017, 76, 973-974.

85 Z. Xu, S. Wu, G. Huang, H. Ding, R. Gui and B. Zhu, Mater. Lett., 2017, 195, 131-135.

86 X. Wu, X. X. Chen, B. N. Song, Y. J. Huang, Z. Li, Z. Chen, T. D. James and Y. B. Jiang, Chemistry, 2014, 20, 1179311799.

87 X. X. Chen, X. Wu, P. Zhang, M. Zhang, B. N. Song, Y. J. Huang, Z. Li and Y. B. Jiang, Chem. Commun., 2015, 51, 13630-13633.

88 C. Sobieski, M. J. Fitzpatrick and S. J. Mennerick, J. Neurosci., 2017, 37, 1888-1899.

89 Z. Zhang, F. Liu and J. Chen, Cell, 2017, 170, 483-491.

90 M. Maffei, E. Longa, A. Sabatini, A. Vacca and S. Iotti, Eur. Biophys. J., 2017, 46, 195-202.

91 R. H. Takahashi, T. Nagao and G. K. Gouras, Pathol. Int., 2017, 67, 185-193.

92 C. Zhang, A. Griciuc, E. Hudry, Y. Wan, L. Quinti, J. Ward, A. M. Forte, X. Shen, C. Ran, D. R. Elmaleh and R. E. Tanzi, Sci. Rep., 2018, 8, 1144.

93 E. Cabrera, P. Mathews, E. Mezhericher, T. G. Beach, J. Deng, T. A. Neubert, A. Rostagno and J. Ghiso, Biochim. Biophys. Acta, Mol. Basis Dis., 2018, 1864, 208-225.

94 K. H. Han, B. M. Arlian, M. S. Macauley, J. C. Paulson and R. A. Lerner, Proc. Natl. Acad. Sci. U. S. A., 2018, 115, E372-E381.

95 B. Baumann, A. Woehrer, G. Ricken, M. Augustin, C. Mitter, M. Pircher, G. G. Kovacs and C. K. Hitzenberger, Sci. Rep., 2017, 7, 43477.

96 J. Sedó, J. Saiz-Poseu, F. Busqué and D. Ruiz-Molina, Adv. Mater., 2013, 25, 653-701.

97 L. Eichhorn, F. Erdfelder, F. Kessler, R. C. Dolscheidpommerich, B. Zur, U. Hoffmann, R. K. Ellerkmann and R. Meyer, Int. J. Sports Med., 2016, 38, 85-91.

98 A. D. Andersen, M. Blaabjerg, M. Binzer, A. Kamal, H. Thagesen, T. W. Kjaer, E. Stenager and J. B. P. Gramsbergen, J. Neurochem., 2017, 141, 614-625.

99 D. Seto, T. Maki, N. Soh, K. Nakano, R. Ishimatsu and T. Imato, Talanta, 2012, 94, 36-43.

100 Z. Wu, M. Li, H. Fang and B. Wang, Bioorg. Med. Chem. Lett., 2012, 22, 7179-7182.

101 E. J. Jun, H. Liu, Y. C. Ji, Y. L. Jin and J. Yoon, Sens. Actuators, B, 2013, 176, 611-617.

102 T. Ptak, P. Młynarz, A. Dobosz, A. Rydzewska and M. Prokopowicz, J. Mol. Struct., 2013, 1040, 59-64.

103 J. S. A. Devi, B. Aswathy, S. Asha and S. George, J. Anal. Chem., 2017, 72, 445-459.

104 R. J. Aitken, Mol. Reprod. Dev., 2017, 84, 1039-1052.

105 B. Xiao, J. Y. Goh, L. Xiao, H. Xian, K. L. Lim and Y. C. Liou, J. Biol. Chem., 2017, 292, 16697-16708.

106 L. Du, N. Ni, M. Li and B. Wang, Tetrahedron Lett., 2010, 51, 1152-1154.
107 X. Q. Zhan, B. Y. Su, H. Zheng and J. H. Yan, Anal. Chim. Acta, 2010, 658, 175-179.

108 E. V. Lampard, A. C. Sedgwick, X. Sun, K. L. Filer, S. C. Hewins, G. Kim, J. Yoon, S. D. Bull and T. D. James, ChemistryOpen, 2018, 7, 262-265.

109 Y. Liu, J. Niu, J. Nie, F. Meng and W. Lin, New J. Chem., 2017, 41, 3320-3325.

110 D. Srikun, E. W. Miller, D. W. Domaille and C. J. Chang, J. Am. Chem. Soc., 2008, 130, 4596-4597.

111 E. Lindberg and N. Winssinger, ChemBioChem, 2016, 17, 1612-1615.

112 C. Jia, J. Tang, S. Lu, Y. Han and H. Huang, J. Fluoresc., 2016, 26, 121-127.

113 P. Mahata, S. K. Mondal, D. K. Singha and P. Majee, Dalton Trans., 2016, 46, 301-328.

114 A. R. Lippert, T. Gschneidtner and C. J. Chang, Chem. Commun., 2010, 46, 7510-7512.

115 J. Xu, J. Zhai, Y. Xu, J. Zhu, Y. Qin and D. Jiang, Analyst, 2016, 141, 2380-2383.

116 R. Radi, J. Biol. Chem., 2013, 288, 26464-26472.

117 K. B. Li, L. Dong, S. Zhang, W. Shi, W. P. Jia and D. M. Han, Talanta, 2017, 165, 593-597.

118 X. Wu, X. Sun, Z. Guo, J. Tang, Y. Shen, T. D. James, H. Tian and W. Zhu, J. Am. Chem. Soc., 2014, 136, 3579-3588.

119 W. Zhai, X. Sun, T. D. James and J. S. Fossey, Chem.-Asian J., 2015, 10, 1836-1848.

120 M. Li, H. Ge, R. L. Arrowsmith, V. Mirabello, S. W. Botchway, W. Zhu, S. I. Pascu and T. D. James, Chem. Commun., 2014, 50, 11806-11809.

121 D. Maity, N. Hari and S. Mohanta, ChemistrySelect, 2017, 2, 9037-9045.

122 S. K. Kim, K. M. K. Swamy, S. Y. Chung, H. N. Kim, J. K. Min, Y. Jeong and J. Yoon, Tetrahedron Lett., 2010, 51, 32863289.

123 M. Li, Z. Liu, H. C. Wang, A. C. Sedgwick, J. E. Gardiner, S. D. Bull, H. N. Xiao and T. D. James, Dyes Pigm., 2017, 149, 669-675.

124 X. Wu, X. X. Chen, B. N. Song, Y. J. Huang, W. J. Ouyang, Z. Li, T. D. James and Y. B. Jiang, Chem. Commun., 2014, 50, 13987-13989.

125 C. Paolucci, I. Khurana, A. A. Parekh, S. Li, A. J. Shih, H. Li, I. J. Di, J. D. Albarracincaballero, A. Yezerets and J. T. Miller, Science, 2017, 357, 898-903.

126 Y. Zhou, H. Dong, L. Liu, M. Li, K. Xiao and M. Xu, Sens. Actuators, B, 2014, 196, 106-111.

127 Y. Kong, J. Shen and A. Fan, Anal. Sci., 2017, 33, 925-930.

128 E. P. Randviir and C. E. Banks, TrAC, Trends Anal. Chem., 2015, 64, 75-85.

129 S. T. Wang, Y. W. Sie, C. F. Wan and A. T. Wu, J. Lumin., 2016, 173, 25-29.

130 A. a. O. El-Ballouli, Y. Zhang, S. Barlow, S. R. Marder, M. H. Al-Sayah and B. R. Kaafarani, Tetrahedron Lett., 2012, 53, 661-665.

131 X. Liu, T. Li, Q. Wu, X. Yan, C. Wu, X. Chen and G. Zhang, Talanta, 2017, 165, 216.

132 T. Tian, Y. He, Y. Ge and G. Song, Sens. Actuators, B, 2017, 240, 1265-1271. 
133 T. N. Narayanan, S. Alwarappan and M. O. Valappil, Curr. Org. Chem., 2015, 19, 1163-1175.

134 X. R. Cheng, B. Y. Hau, T. Endo and K. Kerman, Biosens. Bioelectron., 2014, 53, 513-518.

135 L. Liu, N. Xia, Y. Xing and D. H. Deng, Int. J. Electrochem. Sci., 2013, 8, 11161-11174.

136 M. Li, S. Y. Xu, A. J. Gross, J. L. Hammond, P. Estrela, J. Weber, K. Lacina, T. D. James and F. Marken, ChemElectroChem, 2015, 2, 867-871.

137 B. Wang, S. Takahashi, X. Du and J. Anzai, Biosensors, 2014, 4, 243-256.

138 N. Xia, X. Wang, D. Deng, G. Wang, H. Zhai and S. J. Li, Int. J. Electrochem. Sci., 2013, 8, 9714-9722.

139 A. Thakur, D. Mandal, S. Sao and S. Ghosh, J. Organomet. Chem., 2012, 715, 129-135.

140 M. Li, W. Zhu, F. Marken and T. D. James, Chem. Commun., 2015, 51, 14562-14573.

141 Y. Zhou, H. Dong, L. Liu, J. Liu and M. Xu, Biosens. Bioelectron., 2014, 60, 231-236.

142 G. Wulff, Pure Appl. Chem., 1982, 54, 2093-2102.

143 M. M. Muscatello, L. E. Stunja and S. A. Asher, Anal. Chem., 2009, 81, 4978-4986.

144 W. Wu, T. Zhou, J. Shen and S. Zhou, Chem. Commun., 2009, 4390-4392.

145 J. K. Awino, R. W. Gunasekara and Z. Yan, J. Am. Chem. Soc., 2016, 138, 9759-9762.

146 A. L. Bulin, M. Kucinska, M. Broekgaarden, E. Briars, I. Rizvi and T. Hasan, Photodiagn. Photodyn. Ther., 2017, 17, A67-A68.

147 M. Liu, O. Voznyy, R. Sabatini, F. P. García de Arquer, R. Munir, A. H. Balawi, X. Lan, F. Fan, G. Walters, A. R. Kirmani, S. Hoogland, F. Laquai, A. Amassian and E. H. Sargent, Nat. Mater., 2016, 16, 258-263.

148 C. Hunsur Ravikumar, J. Schiffman and B. Geetha, Quantum Dots as Fluorescent Probes: Synthesis, Surface Chemistry, Energy Transfer Mechanisms, and Applications, 2018.

149 L. Zhang, Z. Y. Zhang, R. P. Liang, Y. H. Li and J. D. Qiu, Anal. Chem., 2014, 86, 4423-4430.

150 S. Liu, F. Shi, X. Zhao, L. Chen and X. Su, Biosens. Bioelectron., 2013, 47, 379-384.

151 M. Zhou, J. Xie, S. Yan, X. Jiang, T. Ye and W. Wu, Macromolecules, 2014, 47, 6055-6066.

152 T. E. Brown and K. S. Anseth, Chem. Soc. Rev., 2017, 46, 6532-6552.

153 J. Wackerlig and R. Schirhagl, Anal. Chem., 2016, 88, 250261.

154 L. Li, Y. Lu, Z. Bie, H. Y. Chen and Z. Liu, Angew. Chem., 2013, 52, 7451-7454.
155 M. Ghaani, N. Nasirizadeh, S. A. Y. Ardakani, F. Z. Mehrjardi, M. Scampicchio and S. Farris, Anal. Methods, 2016, 8, 1103-1110.

156 K. Yum, T. P. Mcnicholas, B. Mu and M. S. Strano, J. Diabetes Sci. Technol., 2013, 7, 72-87.

157 M. B. Lerner, N. Kybert, R. Mendoza and R. Villechenon, Appl. Phys. Lett., 2013, 102, 183113-183114.

158 Q. Wang, I. Kaminska, J. Niedziolkajonsson, M. Opallo, M. Li, R. Boukherroub and S. Szunerits, Biosens. Bioelectron., 2013, 50, 331-337.

159 T. V. Shishkanova, P. Fitl, V. Král and J. Barek, J. Electroanal. Chem., 2016, 761, 106-111.

160 S. K. Basiruddin and S. K. Swain, Mater. Sci. Eng., C, 2016, 58, 103-109.

161 G. Ouyang, G. Chen, J. Qiu, J. Xu, X. A. Fang, Y. Liu, S. Liu, R. Jiang, T. Luan and F. Zeng, Chem. Sci., 2016, 7, 14871495.

162 G. Ouyang, K. D. Oakes, L. Bragg, S. Wang, H. Liu, S. Cui, M. R. Servos, D. G. Dixon and J. Pawliszyn, Environ. Sci. Technol., 2011, 45, 7792-7798.

163 O. P. Togunde, K. D. Oakes, M. R. Servos and J. Pawliszyn, Environ. Sci. Technol., 2012, 46, 5302-5309.

164 F. S. Mirnaghi and J. Pawliszyn, Anal. Chem., 2012, 84, 8301-8309.

165 W. J. Ramsay and H. Bayley, Angew. Chem., Int. Ed. Engl., 2018, 57, 2841-2845.

166 T. Nishino, H. Shiigi, M. Kiguchi and T. Nagaoka, Chem. Commun., 2017, 53, 5212-5215.

167 W. Zhang, W. Liu, P. Li, H. Xiao, H. Wang and B. Tang, Angew. Chem., 2014, 126, 12697-12701.

168 M.-H. Park, E. Reátegui, W. Li, S. N. Tessier, K. H. K. Wong, A. E. Jensen, V. Thapar, D. Ting, M. Toner, S. L. Stott and P. T. Hammond, J. Am. Chem. Soc., 2017, 139, 2741-2749.

169 A. Matsumoto, H. Cabral, N. Sato, K. Kataoka and Y. Miyahara, Angew. Chem., Int. Ed., 2010, 49, 5494-5497.

170 S. Deshayes, H. Cabral, T. Ishii, Y. Miura, S. Kobayashi, T. Yamashita, A. Matsumoto, Y. Miyahara, N. Nishiyama and K. Kataoka, J. Am. Chem. Soc., 2013, 135, 15501-15507.

171 H. Y. Chen, J. R. Wei, J. X. Pan, W. Zhang, F. Q. Dang, Z. Q. Zhang and J. Zhang, Biosens. Bioelectron., 2017, 91, 328-333.

172 A. Szwagierczak, S. Bultmann, C. S. Schmidt, F. Spada and H. Leonhardt, Nucleic Acids Res., 2010, 38, e181.

173 A. Matsumoto, K. Kataoka and Y. Miyahara, Polym. J., 2015, 46, 483-491.

174 P. M. Cal, R. F. Frade, C. Cordeiro and P. M. Gois, Chemistry, 2015, 21, 8182-8187.

175 Z. Li, Q. Huang, Y. Liu, Q. Wang, L. Wang, S. Xiao, F. Bi and J. Ding, Materials, 2017, 10, 170. 